\title{
Wahl und Wettbewerb als normative Steuerungsinstrumente für die Krankenhausversorgung in der Schweiz
}

\author{
Friso Ross
}

Abkürzungen $\quad 359$

$\begin{array}{ll}\text { I. Grundlagen } & 360\end{array}$

1. Überblick $\quad 360$

2. Kernfragen von Wettbewerb und Regulierung 362

2.1. Die Rolle der Krankenhausversorgung 362

2.2. Kostenbegrenzung und -kontrolle 363

2.3. Normative Steuerung und die politische Diskussion 367

2.3.1. Die freie Wahl des Versicherers 367

2.3.2. Zusatzversicherer $\quad 368$

2.3.3. Spitalangebot 368

2.3.4. Der Staat als Multiakteur $\quad 369$

2.3.5. Wettbewerb und wettbewerbliche Elemente $\quad 370$

$\begin{array}{ll}\text { 2.3.6. Preisbildung und Tarife } & 370\end{array}$

3. Die Krankenhausversorgung 371

3.1. Leistungen im Krankenhaussektor $\quad 372$

3.2. Organisationsstruktur des Krankenhaussektors $\quad 374$

3.3. Rechtlicher Rahmen $\quad 378$

3.4. Beziehung zwischen Patient, Leistungsträger und -erbringer $\quad 379$

4. Wettbewerb und Gesundheitsversorgung $\quad 380$

4.1. Verfassungsrechtliche Fundierung 380

4.2. Wettbewerbsrechtlicher Rahmen 381

4.3. Wettbewerb im Gesundheitswesen 382

II. Märkte - Wettbewerb und Regulierung in der Krankenhausversorgung 383

1. Verbraucherorientierte Anreize der Krankenhauswahl 383

1.1. Obligatorische Krankenversicherung 383

1.1.1. Recht auf Behandlung $\quad 383$

1.1.2. Auswahl und Kostendeckung $\quad 384$

1.1.3. Auswahl und Einweisung $\quad 386$

1.1.4. Auswahl und Aufklärungspflicht 386

1.1.5. Auswahl und Information 387

$\begin{array}{ll}\text { 1.1.6. Auswahl und Zugang } & 387\end{array}$

1.1.7. Eingeschränkte Auswahl aufgrund des Versicherungsverhältnisses 388

$\begin{array}{ll}\text { 1.2. Zusatzversicherung } & 389\end{array}$

2. Verbraucherorientierte Anreize der Versicherungswahl 391

$\begin{array}{ll}\text { 2.1. Obligatorische Krankenversicherung } & 391\end{array}$

2.1.1. Wahlfreiheit, Versicherungspflicht und Kontrahierungszwang 391

2.1.2. Wahlfreiheit und Pflichtmitgliedschaften nach Arbeits- oder Verbandsrecht

2.1.3. Leistungen und Prämien 392

2.1.4. Prämien bei besonderen Versicherungsformen 393 
2.1.5. Kostenerstattungsprinzip und Naturalleistungsprinzip 394

2.2. Zusatzversicherung 395

3. Wettbewerbsbeziehungen zwischen Kostenträgern und Krankenhäusern 396

3.1. Obligatorische Krankenversicherung 396

3.1.1. Tarifvertrag, Behördentarif, Ersatztarif 397

3.1.2. Tarifvertragsparteien und Wettbewerb 397

3.1.3. Tarifvertragsinhalt und Preisüberwachung 397

3.1.4. Tarife und Pauschalen 398

3.2. Zusatzversicherung $\quad 399$

4. Wettbewerb zwischen Krankenhäusern 399

4.1. Struktur und Status $\quad 400$

4.2. Spitalplanung und Spitallisten 401

4.3. Subventionen 402

4.4. Preiswettbewerb? 403

4.5. Konzentrationsprozeß 404

4.6. Fusionen 404

5. Wettbewerb zwischen Versicherungen 405

5.1. Obligatorische Krankenversicherung 405

$\begin{array}{ll}\text { 5.1.1. Struktur } & 405\end{array}$

5.1.2. Marktauftreten $\quad 406$

5.1.3. Prämiengestaltung 406

5.1.4. Risikoausgleich 406

5.2. Zusatzversicherung $\quad 407$

III. Ergebnisse: Wahl und Wettbewerb im regulierten System 409

Literatur 


\section{Abkürzungen}

BAG

BBl

BfS

BG

BGE

BR

BSV

BV

CHF

DRG

EDI

EU

EVG

FINMA

FMH

GesG

HMO

KG

KLV

KV

KVG

KVUG

KVV

OR

PRV

PüG

ReKo

RPW

RUKV

SR

StGB

VKL

VORA

VVG

VwVG

ZGB
Bundesamt für Gesundheit

Bundesblatt der Schweizerischen Eidgenossenschaft

Bundesamt für Statistik

Bundesgericht

Entscheidungen des Bundesgerichts

Bundesrat

Bundesamt für Sozialversicherungen

Bundesverfassung der Schweizerischen Eidgenossenschaft

Schweizer Franken

Diagnosis related groups

Eidgenössisches Departement des Inneren

Europäische Union

Eidgenössisches Versicherungsgericht

Eidgenössische Finanzmarktaufsicht

Féderation de médecins suisse

Gesundheitsgesetz

Health Maintenance Organization

Kartellgesetz

Verordnung über Leistungen in der Krankenversicherung

Krankenversicherung

Krankenversicherungsgesetz

Kranken- und Unfallversicherungsgesetz

Krankenversicherungsordnung

Obligationenrecht

Patientenrechtsverordnung

Preisüberwachungsgesetz

Rekurskommission

Recht und Politik des Wettbewerbs

Rechtsprechung zur Kranken- und Unfallversicherung

Systematische Sammlung des Bundesrechts

Strafgesetzbuch

Kostenermittlungs- und Leistungserfassungsverordnung

Risikoausgleichsverordnung

Versicherungsvertragsgesetz

Verwaltungsverfahrensgesetz

Zivilgesetzbuch 


\section{Grundlagen}

\section{1. Überblick}

Das Schweizer Krankenversicherungsrecht wird vom Krankenversicherungsgesetz $\mathrm{KVG}^{1}$ geprägt und dadurch von der allgemeinen obligatorischen Versicherungspflicht aller Einwohner der Schweiz. Somit ist es den Einwohnern zunächst nicht freigestellt, daß sie sich versichern. Aber auch die Handlungsspielräume der Leistungsträger und Leistungserbringer werden grundsätzlich vom System der obligatorischen Krankenversicherung mitbestimmt. Insgesamt bedeutet all dies eine starke Prägung des Gesundheitswesens und damit des Krankenhausbereiches durch die Existenz des obligatorischen Krankenversicherungssystems.

Innerhalb dieses Obligatoriums können sich jedoch die dort beteiligten Akteure in einem gewissen Umfang frei entfalten. Dieser Freiraum wird durch das obligatorische System grundsätzlich gefördert. Er bedeutet nicht nur, daß die Versicherten zwischen den Leistungsträgern und deren unterschiedlichen Angeboten wählen können, sondern auch, daß grundsätzlich sowohl Träger als auch Erbringer Private sein können. Einen staatlichen Gesundheitsdienst oder eine nur staatliche Versicherungsstruktur ist jedenfalls nicht das Ziel des Obligatoriums. Außerhalb dieses Obligatoriums, welches nur die medizinische Grundversorgung gewährleistet, besteht das System der Zusatzversicherungen. Dieses ist weniger reglementiert und entspricht eher dem freien Markt. Da sich zahlreiche Zusatzleistungen auf Leistungen in Krankenhäusern beziehen, ist auch das marktwirtschaftliche Zusatzversicherungswesen von großer Bedeutung für den Krankenhaussektor der Schweiz.

Die Einführung des neuen KVG, mit Obligatorium und Kontrahierungszwang einerseits, mit Auswahlrechten und Wettbewerbselementen andererseits, war eine direkte Reaktion auf die Zustände, welche das alte $\mathrm{KUVG}^{2}$ befördert hatte: Das Krankenversicherungssystem nach dem KUVG beruhte auf einer den Kantonen überlassenen Entscheidungsgewalt darüber, ob der jeweilige Kanton für bestimmte Personengruppen des Kantons eine Versicherungspflicht einführte. Damit ergab sich schweizweit ein buntes Bild obligatorischer Versicherung. Dem kam gleich, daß die Kantone wiederum ihren Gemeinden die Befugnis einräumen konnten, selbst für ihren Wirkungsbereich zu entscheiden, wer obligatorisch zu versichern sei, so daß es nicht nur zwischen den Kanto-

1 Bundesgesetz vom 18. März 1994 über die Krankenversicherung (SR 832.10). Im Folgenden werden alle Normen des Bundes, wie in der Schweiz üblich, nach der offiziellen Systematischen Sammlung des Bundesrechts (SR) zitiert. Gesetzesrevisionen werden nach dem Bundesblatt der Schweizerischen Eidgenossenschaft (BBl) zitiert. Beide Quellen sind online verfügbar: Die SR unter http://www.admin.ch/ch/d/sr/sr.html und das BBl unter http://www.admin.ch/ch/d/ff/index.html.

2 Bundesgesetz vom 13. Juni 1911 über die Kranken- und Unfallversicherung, mehrfach revidiert, durch das KVG aufgehoben. 
nen sondern auch innerhalb eines Kantons große Unterschiede gab, wer dem Obligatorium unterstellt wurde. ${ }^{3}$ Hinzu kam noch, daß zwar jeder Schweizer, nicht jedoch jeder Ausländer gemäß Art. 5 Abs. I KUVG das Recht hatte, einer Krankenkasse beizutreten. Dieses im Prinzip Schweizer Bürgern vorbehaltene Recht unterlag dem grundsätzlichen Vorbehalt der statuarischen Aufnahmebedingungen der jeweiligen Krankenkasse. Insgesamt konnten die Krankenversicherungen durch ihre Statuten Risikoselektion betreiben, indem sie etwa nur Mitglieder bestimmter Berufs- oder Altersgruppen aufnahmen, bestimmte Krankheiten eines Versicherten für fünf Jahre von der Versicherung ausschlossen oder die Beitragshöhe in Abhängigkeit zu Alter und einzelnen Krankheiten setzten. Wenngleich nicht alle Krankenversicherungen hiervon Gebrauch machten, vor allem größere und regionalübergreifende Krankenversicherungen sich für jedermann öffneten, gab es dennoch die Tendenz einzelner, sogenannter Billigkassen, älteren, einkommensschwachen oder kranken Personen den Zugang faktisch zu verwehren, während sie durch geringere Prämien jüngere, gesündere und finanzstärkere Personen anzogen. ${ }^{4}$

Das Schweizer Krankenversicherungssystem nach dem alten KUVG mit seiner sehr wettbewerblichen Ausrichtung führte einerseits zum Entstehen bzw. Herausbilden von zahlreichen Krankenkassen mit eher sogenannten guten Risiken und andererseits zur finanziellen Belastung derjenigen Krankenkassen, die eine Risikoselektion nicht im genannten Maße betrieben. Folge hiervon war eine Kostenexplosion und damit eng verbunden eine Erhöhung der Beiträge für Versicherte, die in Krankenkassen mit eher sogenannten schlechten Risiken versichert waren. Die Last des Krankenversicherungssystems trugen damit jene, denen als Alte, Kranke oder Einkommensschwache der Zugang zu finanzstarken und preisgünstigen Krankenkassen verwehrt blieb. Auf diese Situation reagierte der Schweizer Gesetzgeber 1991 mit einem dringlichen Bundesbeschluß, der schon im Titel und in den Gesetzgebungsmotiven keinen Zweifel daran ließ, was sein vorrangiges Ziel war: „Bundesbeschluß ... gegen die Entsolidarisierung in der Krankenversicherung" ${ }^{\circ}$. Kern dieser legislativen Maßnahme war die Einrichtung eines Risikoausgleichs zwischen den Krankenversicherern.

Da sich die Zustände dennoch insgesamt nicht veränderten, erarbeitete man einen Entwurf für ein neues Krankenversicherungsrecht. Das hieraus entstandene KVG vom 18. März 1994, in Kraft getreten zu Beginn des Jahres 1996, hinterließ eine deutliche Zäsur im Krankenversicherungssystem. Grundelemente des KVG sind nun die obligatorische Versicherungspflicht der Schweizer Wohnbevölkerung, die grundsätzliche Wahlfreiheit der Versicherten zwischen den Versicherern, der Aufnahmezwang seitens der Versicherer in ihrem Wirkungskreis und schließlich das Prinzip der Einheitsprämie, was nichts anderes heißt, als daß der Versicherer die Prämien unabhängig von Geschlecht, Alter, Einkommen und Krankheiten erheben muß und nur regional Abstufungen vor-

3 Maurer, Bundessozialversicherungsrecht, S. 252.

4 Maurer, Bundessozialversicherungsrecht, S. 265-269 und 259.

5 BBl. 1991, IV, 917-932. 
nehmen darf. ${ }^{6}$ Die Prämien, also der Beitrag, wird weiterhin einkommensunabhängig pro Versicherten erhoben und die Prämienkalkulation fällt in die Regelungsbefugnis der Krankenkasse; dem Versicherten können aber geringere Prämien angeboten werden, wenn er etwa seine Kostenbeteiligung erhöht, seine Wahlfreiheit bezüglich der Leistungserbringer einschränkt oder an bestimmten Programmen wie HMO, DRG oder Integrierter Versorgung teilnimmt. ${ }^{7}$ Durch die Prämienkalkulation seitens der Krankenkassen und insbesondere die Angebote zur Prämienreduktion soll, bei gleichbleibender Leistungsberechtigung der Versicherten nach dem KVG, ein Wettbewerb um die Versicherten stattfinden.

\section{Kernfragen von Wettbewerb und Regulierung}

\subsection{Die Rolle der Krankenhausversorgung}

Der Krankenhaussektor ist für das gesamte Gesundheitswesen und für das Krankenversicherungswesen von herausragender Bedeutung. Ihm obliegt nicht nur der bundesstaatliche und zumeist auch der jeweilige kantonale Auftrag, Spitzenmedizin zu gewährleisten und für sie Forschung zu treiben. ${ }^{8}$ Vielmehr kann man schon an bloßen Zahlen ablesen, wie bedeutend er ist:

Die Krankenhäuser (im Folgenden der Terminologie folgend Spitäler genannt) sind der größte Arbeitgeber im Gesundheitswesen: Von den 375.000 Beschäftigten im Gesundheitswesen ${ }^{9}$ - inklusive Industrie, Handel, Verwaltung und Prävention - waren im Jahre 2005129.800 in den Spitälern tätig ${ }^{10}$, also insgesamt 34,6 Prozent ${ }^{11}$. Dabei ist ein stetiger Anstieg zu verzeichnen: 1995 arbeiteten 115.000, 2001 schon 121.000 und 2007 bereits 131.000 Beschäftigte in den Spitälern. ${ }^{12}$

Für die Spitäler wurden im Jahre 2007 von der obligatorischen Krankenversicherung $37 \%$ des Gesamtbruttoleistungsbudgets von 21.6 Mrd. CHF ausgegeben, ${ }^{13}$ wobei die

6 Maurer, Krankenversicherungsrecht, S. 34-38 und 143-144.

7 Eugster, Krankenversicherung, Rz. $737 \mathrm{ff}$.

8 Siehe Interkantonale Vereinbarung über die hochspezialisierte Medizin (IVHSM) vom 14. März 2008, online verfügbar unter: http://www.gdk-cds.ch/fileadmin/pdf /Themen/ Gesundheitsversorgung/Hochspezialisierte_Medizin/IVHSM_20080416_d.pdf

9 Hier, wie im Folgenden, ist die Anzahl der Beschäftigten in Vollzeitäquivalenten gemeint.

10 Bundesamt für Statistik, Beschäftigte im Gesundheitswesen 1995-2005, S. 9.

11 Die von Boos, Soziales Dilemma und die Organisation des Krankenhauses, S. 40, im Jahre 2002 getroffene Aussage, von den 346000 Beschäftigten im Gesundheitswesen seien 63\% stationär tätig, umfaßt neben den Beschäftigten in den Spitälern auch die Beschäftigten in Heimen und anderen sozialmedizinischen Einrichtungen.

12 Bundesamt für Statistik, Beschäftigte im Gesundheitswesen 1995-2005, S. 30; Bundesamt für Statistik, Krankenhausstatistik 2007, Tabelle B2.

13 Bundesamt für Gesundheit, Statistik der obligatorischen Krankenversicherung 2007 - Grafiken und Kommentare, S. 15. 
Aufwendungen für stationäre Leistungen gemessen an der Gesamtsumme 24\% und für ambulante Leistungen 13\% ausmachen. Im Vergleich liegt der Anteil für ambulante Leistungen von Ärzten bei $22 \%$ und für Arzneimittel bei $20 \% .{ }^{14}$

Darüber hinaus spielen auch die privaten Leistungserbringer innerhalb des Spitalsektors eine wichtige Rolle: Von den 333 zur Erbringung von obligatorischen Leistungen zugelassenen Spitälern waren im Jahre 2007127 private Einrichtungen und 206 öffentlich-rechtliche oder öffentlich subventionierte Spitäler. ${ }^{15}$ Dabei ist beachtlich, daß zwar die Anzahl der zugelassenen Spitäler insgesamt zurückgeht, jedoch der Rückgang bei den privaten Einrichtungen weniger stark ist als bei den öffentlich-rechtlichen oder öffentlich subventionierten Spitälern. ${ }^{16}$

Auch die Bedeutung für die privaten Zusatzversicherungen hat zugenommen. So stieg die Anzahl von Spitalzusatzversicherungen seit der Reform des Krankenversicherungswesens 1996 bis zum Jahre 2003. Hatten 1996 etwa 61\% der obligatorisch Versicherten eine solche Police, so waren es 2003 immerhin schon 71\%. ${ }^{17}$ Dieser hohe Wert ist bis heute annähernd gleich geblieben. ${ }^{18}$

Letztlich ist die Zunahme der Spitalzusatzversicherungen auch dafür verantwortlich, daß die Spitäler einen großen Anteil privat zahlender Patienten haben. So lag schon im Jahre 2000 bei öffentlich-rechtlichen bzw. öffentlich subventionierten Spitälern der Anteil von Fällen in den Abteilungen für Privatpatienten durchschnittlich bei $18 \%$ und bei den Privatspitälern bei immerhin 40\%. ${ }^{19}$

\subsection{Kostenbegrenzung und-kontrolle}

Die Kosten im Gesundheitssektor sind trotz der Reform des Krankenversicherungswesens im Jahre 1996 und der damit zusammenhängenden Einführung bzw. Beibehaltung wettbewerblicher Elemente teilweise linear gestiegen, teilweise sind die Kosten gleich geblieben oder so gar niedriger geworden: Betrug der Gesamtanteil der Kosten für das Gesundheitswesen am BIP 1996 etwa 10\%, so lag er 2002 bei 11,5\%.20 Dieser

14 Im Jahre 2003 wurden 34,8\% des Gesamtleistungsbudgets von 17.9 Mrd. CHF für die Spitäler ausgegeben, wobei die Aufwendungen für stationäre Leistungen gemessen am Budget 22,9\% und für ambulante Leistungen 11,9\% ausmachten, der Anteil für ambulante Leistungen von Ärzten bei $22,3 \%$ und für Arzneimittel bei 22,0 \% lag. Vgl. Bundesamt für Gesundheit, Statistik der obligatorischen Krankenversicherung 2003, S. 9.

15 Zahnd, Kennzahlen der Schweizer Spitäler, S. 175.

16 Bundesamt für Gesundheit, Kennzahlen der Schweizer Spitäler 2005, S. 7.

17 Bundesamt für Gesundheit, Statistik der obligatorischen Krankenversicherung 2003, S. 37.

18 Bundesamt für Gesundheit, Statistik der obligatorischen Krankenversicherung 2007 - Tabellen und Beilagen, Tabelle 9.11.

19 Indra, SwissDRG, S. 193.

20 Bundesamt für Gesundheit, Statistik der obligatorischen Krankenversicherung 2003, S. 42. 
Prozentwert hat sich seither kaum verändert 21 , ist in der Tendenz eher auf ca. $11 \% \mathrm{zu}-$ rückgegangen, ${ }^{22}$ so daß man zwar seit 1996 einen Anstieg der Gesundheitskosten verzeichnen kann; dieser ist jedoch seit 2002 in Beziehung zum BIP zumindest aufgehalten worden. Ähnliches läßt sich für die Rechnungssalden der sozialen Krankenversicherung, also den Differenzen zwischen Einnahmen und Ausgaben, feststellen: Gab es noch 1990 einen Überschuß von 260 Mio. CHF, so war seit Mitte der 1990er Jahre festzustellen, daß sich ein dauerhaftes Minus ergab: 199582 Mio. CHF, 199949 Mio. CHF, 2000309 Mio. CHF, 2001790 Mio. CHF, 2002224 Mio. CHF. ${ }^{23}$ Seitdem gibt es eine Trendwende. So konnten im Jahre 2003 Einnahmeüberschüsse von ca. 600 Mio. CHF, 2004 von über 800 Mio. CHF und 2006 von fast 950 Mio. CHF erzielt werden. ${ }^{24}$

Allerdings sind die Versicherungsprämien trotz aller Reformbemühungen stetig gestiegen: Für die obligatorische Krankenversicherung leisteten alle Versicherten im Jahre 1990 Prämien in Höhe von 6.64 Mrd. CHF, 1995 8.3 Mrd., 1999 10.4 Mrd., 200111.28 Mrd., 200212.48 Mrd.. CHF ${ }^{25}$, 2004 bereits 18 Mrd., 200518.5 Mrd. und 200619.3 Mrd. ${ }^{26}$, und 2007 wurde mit 19.68 Mrd. CHF fast die 20-Milliardengrenze erreicht. ${ }^{27}$ Ein deutlicher Prämienanstieg seit dem Jahre 2000, wenngleich nicht in derselben Höhe wie bei der obligatorischen Krankenversicherung, macht sich auch bei den Zusatzversicherungen, insbesondere bei den Spitalzusatzversicherungen bemerkbar. ${ }^{28}$

Trotz steigender Prämien zeigen wiederum andere Zahlen ein differenzierteres Bild: Die Sozialleistungen für Gesundheit 29 sind zwar sowohl vor als auch nach der Reform von 1996 unvermindert gestiegen, nämlich von 19907.4 Mrd., über 199510 Mrd., 1999 12.4 Mrd., 200114 Mrd. auf 2002 14.7 Mrd. CHF30 und von 2003 16.3 Mrd. über 2004 17.2 Mrd., 2005 18.3 Mrd. auf 2006 18.6 Mrd. CHF. ${ }^{31}$ Doch stiegen die Sozialleistungen für Gesundheit auch nicht stärker an als etwa die Geldleistungen im Alter und waren sogar niedriger angewachsen als die Sozialleistungen für Arbeitsmarktmaßnahmen

21 Bundesamt für Gesundheit, Statistik der obligatorischen Krankenversicherung 2007 - Tabellen und Beilagen, Tabelle 9.19.

22 http://www.bfs.admin.ch/bfs/portal/de/index/themen/14/05/blank/key/internationaler_vergleich.html

23 Bundesamt für Sozialversicherungen, Sozialversicherungsstatistik 2004, S. 20.

24 Bundesamt für Sozialversicherungen, Sozialversicherungsstatistik 2008, S. 143.

25 Bundesamt für Sozialversicherungen, Sozialversicherungsstatistik 2004, S. 22.

26 Bundesamt für Sozialversicherungen, Sozialversicherungsstatistik 2008, S. 148.

27 Bundesamt für Gesundheit, Statistik der obligatorischen Krankenversicherung 2007 - Tabellen und Beilagen, Tabelle 1.01.

28 Vgl. etwa: Bundesamt für Gesundheit, Statistik der obligatorischen Krankenversicherung 2007 Graphiken und Kommentare, S. 46, oder: Bundesamt für Sozialversicherungen, Sozialversicherungsstatistik 2008, S. 148.

29 Die Sozialleistungen für Gesundheit selbst machen etwa 16\% der Gesamtausgaben der Sozialversicherungen aus. Höher liegt der Anteil für Geldleistungen im Alter (43\%), etwas niedriger für Geldleistungen der Invalidität (9\%): Bundesamt für Sozialversicherungen, Sozialversicherungsstatistik 2008, S. 4.

30 Bundesamt für Sozialversicherungen, Sozialversicherungsstatistik 2004, S. 27.

31 Bundesamt für Sozialversicherungen, Sozialversicherungsstatistik 2008, S. 36. 
und die Geldleistungen für Invalidität. ${ }^{32}$ Vielmehr läßt sich sagen, daß die Sozialleistungen für Gesundheit in ähnlichem Maße angewachsen sind wie die gesamten Sozialleistungen in der Schweiz. ${ }^{33}$

Die Kosten der Krankenversicherungen pro Versicherten für Leistungen in den Spitälern sind von 1998 bis 2007 um ca. 63\% gestiegen, während sie bei ambulanten Leistungen durch Ärzte und Arztpraxen nur um 30\% gestiegen sind. ${ }^{34}$ Allerdings gewinnt die Aussagekraft solcher Zahlen eine andere Bedeutung, wenn man die Zunahme von ambulanten Leistungen in den Spitälern betrachtet: Durch die Einführung von HMOModellen, aber auch schon durch die Leistungserweiterung seitens der Spitäler ist es zu einem Anstieg von ambulanten Leistungen durch die Spitäler seit den Reformen gekommen, nämlich von 1998 bis 2007 um 216\%. ${ }^{35}$ Es nimmt daher nicht Wunder, wenn 2007 jeder dritte Franken für ambulante Leistungen von den Krankenversicherern an die Spitäler gezahlt wurde. ${ }^{36}$ Insgesamt heißt dies aber, daß die Zunahme für Kosten pro Versicherten in den Spitälern eben auch mit der Zunahme der Leistungserbringung auf einem Sektor korreliert, der zuvor eher nicht in und von den Spitälern erbracht wurde.

Zusammenfassend lassen sich aber aus den gezeigten Beispielen von Kostenentwicklungen selbst noch keine eindeutigen Aussage darüber ableiten, inwieweit die Reformen des Krankenversicherungswesens wie auch die Einführung bzw. Beibehaltung wettbewerblicher Elemente zur Kostendämpfung beitrugen oder etwa Kosten erst stimulierten. Dabei gibt es weitere Faktoren, die beim momentanen Forschungsstand gänzlich unbekannt sind, jedoch vermuten lassen, daß sie erheblichen Einfluß auf die Kostenentwicklung haben. So sind im Wirtschaftskreislauf insbesondere von bedeutendem Einfluß die allgemeine Inflationsrate wie auch die Preissteigerungen gemessen am BIP.

Allerdings können Teilbereiche ausgemacht werden, die gerade hinsichtlich ihrer wettbewerblichen Funktion wenigstens zur Dämpfung von Kosten geführt haben könnten. Als beste Beispiele für eine solche Vermutung seien hier die wählbaren Franchisen der Versicherten, die Verwaltungskosten der Krankenversicherer und der Anteil der öffentlichen Haushalte am Gesundheitswesen genannt:

Das Modell der wählbaren Franchise beinhaltet, daß der Versicherte seinen jährlichen Eigenanteil an den Kosten erhöht und dafür weniger an jährlicher Prämie zahlt. ${ }^{37}$

32 Folgende Steigerungen sind von 1987 (= Index 100) zu 2006 zu verzeichnen: Sozialleistungen für Gesundheit 290, Geldleistungen im Alter 260, Sozialleistungen für Arbeitsmarktmaßnahmen 338, Geldleistungen für Invalidität 381: Bundesamt für Sozialversicherungen, Sozialversicherungsstatistik 2008, S. 36.

33 Die Sozialleistungen der Gesamtrechnung für die Schweiz stiegen von 100 (1987) auf 271 (2006), nämlich von 38.5 Mrd. auf 104.7 Mrd. CHF: Bundesamt für Sozialversicherungen, Sozialversicherungsstatistik 2008, S. 36 ..

34 Bundesamt für Gesundheit, Statistik der obligatorischen Krankenversicherung 2007 - Tabellen und Beilagen, Tabelle 2.16.

35 Ebenda.

36 Ebenda.

37 Zum Franchise- und Prämiensystem siehe ausführlich II.2.1.4. 
Für diese Form der Minderung von Prämienzahlungen optieren nicht nur immer mehr Versicherte, sondern sie hat gerade bei den Kosten pro Versicherten dazu geführt, daß im Jahre 2002 die Krankenversicherungen für Versicherte mit Wahlfranchise (CHF 2361,-) deutlich weniger an Leistungen zahlen als für Versicherte ohne Wahlfranchise (CHF 3904,-). ${ }^{38}$ Dem kommt gleich, daß die Kosten pro Versicherten, der aufgrund sogenannter HMO- oder Hausarztmodellen eingeschränkt Leistungsangebote der obligatorischen Krankenversicherung in Anspruch nimmt, deutlich geringer sind (CHF 1792,-) als bei einem Versicherten ohne Einschränkung von Leistungsangeboten. 39

Auch bei den Verwaltungskosten scheint einiges dafür zu sprechen, daß die Einführung von Wirtschaftlichkeitskriterien im Krankenversicherungsgesetz Einfluß auf die Kostenentwicklung genommen hat. Während sich die Ausgaben für Sozialleistungen in der obligatorischen Krankenversicherung von 1990 bis 2006 verzweieinhalbfacht haben (von 7.4 auf 18.7 Mrd. CHF), sind die Kosten für Verwaltung und Durchführung der Krankenversicherung im gleichen Zeitraum nur um zwei Fünftel höher geworden (von 740 auf 1083 Mio. CHF). ${ }^{40}$ Dabei wird sicherlich auch eine Rolle gespielt haben, daß die Einführung wettbewerblicher Elemente insgesamt zu einer Verminderung der Anzahl von Krankenversicherungen geführt hat und somit Synergieeffekte auslöste. ${ }^{41}$

Schließlich sind die Kosten für die öffentlichen Haushalte nicht in dem Maße gestiegen wie für die Beitragszahler. Die gesamten Beiträge für die obligatorische Krankenversicherung haben sich von 1990 bis 2006 fast verzweieinhalbfacht (von 6.6 auf 15.9 Mrd. CHF), während die Kosten der öffentlichen Haushalte für Krankenversicherungsleistungen nur um etwa vier Fünftel gestiegen sind (von 1.9 auf 3.3 Mrd. CHF). ${ }^{42}$ War 1990 das Verhältnis zwischen Beiträgen der öffentlichen Haushalte und Beiträgen der Versicherten noch 1:3, so lag dieses Verhältnis 2006 schon bei 1:5.43 Diese Verschiebung zu Lasten der Beiträge der Versicherten und zu Gunsten der öffentlichen Haushalte kann noch nicht abschließend geklärt werden. Jedoch läßt der Umstand, daß die öffentlichen Haushalte verpflichtet sind, bestimmte Leistungen der Krankenversicherung mitzutragen (z.B. Festzuschüsse zu Spitalleistungen oder Prämienverbilligungen), vermuten, daß diese bestimmten Leistungen nicht im selben Maße gestiegen sind wie insgesamt alle Leistungen.

38 Bundesamt für Gesundheit, Statistik der obligatorischen Krankenversicherung 2007 - Tabellen und Beilagen, Tabelle 2.15 .

39 Ebenda.

40 Bundesamt für Sozialversicherungen, Sozialversicherungsstatistik 2008, S. 145.

41 Von 1990 bis 2006 ist die Anzahl von Versicherern der obligatorischen Krankenversicherung von 246 auf 87 geschrumpft: Bundesamt für Gesundheit, Statistik der obligatorischen Krankenversicherung 2003, S. 29; Bundesamt für Gesundheit, Statistik der obligatorischen Krankenversicherung 2007 - Tabellen und Beilagen, Tabelle 2.15.

42 Bundesamt für Sozialversicherungen, Sozialversicherungsstatistik 2008, S. 145.

43 Ebenda. 


\subsection{Normative Steuerung und die politische Diskussion}

Sowohl die normative Steuerung als auch der politische Ansatz hierzu sind für unsere Fragestellung hinsichtlich des Schweizer Systems von außerordentlicher Bedeutung. Denn einerseits hat die Schweiz auf Einführung eines obligatorischen Krankenversicherungssystems gesetzt, um die Gesundheitsvorsorge für jedermann, wie sie schon die Verfassung in Auftrag gibt, ${ }^{44}$ zu gewährleisten. Andererseits hat die Schweiz den Versuch unternommen, wettbewerbliche Elemente innerhalb des Obligatoriums zu installieren, um die Kräfte des freien Marktes zu simulieren bzw. sie mit einzubeziehen. Nicht von ungefähr kam daher der Wille zum Ausdruck, sowohl auf Seiten der Leistungsträger als auch auf Seiten der Leistungsanbieter Private für dieses System zu gewinnen.

Konterkariert wird dies jedoch bereits durch die Tatsache, daß der Staat selbst, vornehmlich die Kantone, sich nicht auf die Durchführung oder die bloße Aufsicht beschränkt, sondern vielmehr Akteur auf den verschiedensten Ebenen ist. Daher ist es das Spannungsverhältnis zwischen garantierter Gesundheitsvorsorge, Förderung wirtschaftlicher Anreize, Ausbau privaten Engagements einerseits und weiterhin staatlicher Dominanz andererseits, welches die normative Steuerung und den politischen Willen prägt:

\subsubsection{Die freie Wahl des Versicherers}

Obwohl kein Einwohner der Schweiz darin frei ist, daß er sich versichert, räumt ihm das Gesetz einen großen Spielraum ein, wie er sich versichert. Insbesondere steht ihm die freie Wahl zu, sich seinen Versicherer auszusuchen. ${ }^{45}$ Doch bereits hier kann er nur auf solche Anbieter zurückgreifen, denen der Staat die Zulassung erteilt hat: Während dies bei den sogenannten sozialen Krankenkassen kaum Probleme bereitet, müßten private Versicherer zahlreiche Auflagen erfüllen, insbesondere hinsichtlich der Rechtsform. ${ }^{46}$ Ihnen wäre es auch gestattet, weitere Versicherungen anzubieten, doch sind die Arten der Versicherungen gemäß Art. 12 Abs. II KVG und Art. 14 KVV47 eingeschränkt. Die genannten Auflagen wie Beschränkungen führen neben anderen Gründen dazu, daß private Versicherungen im Bereich des Obligatoriums keine Rolle spielen. ${ }^{48}$ Das hat wiederum zur Folge, daß der Versicherte eigentlich nur zwischen den verschiedenen sozialen Krankenversicherungen und damit nur innerhalb der mittelbaren Staatsverwaltung auswählen kann.

Trotz dieser faktischen Einschränkung sind die Wahlmöglichkeiten bei den sozialen Krankenversicherungen beträchtlich. Der Versicherte kann wählen zwischen einer „normalen“ obligatorischen Versicherung ohne finanzielle Mehrbelastung, d.h. ohne Wahlfranchise, einer Versicherung mit Wahlfranchise in verschiedenen Abstufungen,

$44 \mathrm{Zu}$ verfassungsrechtlichen Vorgaben vgl. Gächter/Vollenweider, Gesundheitsrecht, Rz. 75ff.

45 Maurer, Das neue Krankenversicherungsrecht, S. 143-150.

46 Art. $11 \mathrm{~b}$ und $13 \mathrm{KVG}$.

47 Verordnung vom 27. Juni 1995 über die Krankenversicherung (SR 832.102).

48 Eugster, Krankenversicherung, Rz. 182. 
einer Versicherung mit Einschränkung des Leistungsangebotes (HMO-/Hausarztmodell) sowie Versicherungen mit bestimmten Bonussystemen. Der Anreiz zur Wahl einer Versicherung mit Mehrkosten oder Leistungseinschränkung wird durch geringere Prämien gesetzt. Diese Wahlmodi mit entsprechendem Prämiennachlaß sind für die Versicherten derart attraktiv, daß im Jahre 2007 nur noch 40\% der Versicherten eine „normale“ Versicherung ohne Wahlfranchise oder ohne Leistungseinschränkung hatten. ${ }^{49}$

\subsubsection{Zusatzversicherer}

Die obligatorische Krankenversicherung garantiert die Grundversorgung, das heißt die medizinisch notwendige Versorgung. Damit ist aus juristischer Sicht der Spielraum für privat abzusichernde medizinische Leistungen eigentlich eher gering; sieht man einmal von Chefarztbehandlung oder plastischen Eingriffen ab. Dennoch ist zu verzeichnen, daß die privaten Haushalte immer mehr Gebrauch von Zusatzversicherungen machen, insbesondere von Spitalzusatzversicherungen. ${ }^{50}$ Damit bleibt zunächst einmal ungewiß, ob die Annahme in der juristischen Lehre ${ }^{51}$, die Grundversorgung schließe alle notwendigen Leistungen des Spitals mit ein, so richtig ist und ob die Aussage, die Spitalzusatzversicherungen gewährleisteten wohl eher Annehmlichkeiten, wirklich zutrifft.

Beachtlicher für die normative Steuerung ist jedoch die Ausgestaltung der Zusatzversicherungen. Dem Willen des Gesetzgebers entsprechend, sollte ein facettenreiches Angebot entstehen. Festzustellen ist, daß sich die Angebote der Zusatzversicherer, insbesondere im Spitalwesen, immer mehr gleichen. Da das Zusatzversicherungswesen aber in vollem Maße dem Wettbewerbsrecht untersteht, könnten solche inhaltsgleichen Angebote dazu führen, daß die Wettbewerbskommission ermitteln müßte, falls man hinter solchen Inhalten Wettbewerbsabsprachen vermuten würde. 52

\subsubsection{Spitalangebot}

Die Leistungserbringer, also die Spitäler, können obligatorische Leistungen nach dem KVG nur dann erbringen, wenn sie zugelassen worden sind. ${ }^{53}$ Die Zulassung für den jeweiligen Kanton gibt der jeweilige Kanton. Dieser betreibt aber in aller Regel zur Sicherung der Grundversorgung - selbst mindestens ein oder zwei Spitäler, selbst wenn der Kanton einwohnerschwach ist und der Nachbarkanton über ausgezeichnete, leicht erreichbare Infrastruktur verfügt. Damit fungiert der Kanton - als Betreiber eigener Spitäler - als Zulassungsbehörde für Spitäler in fremder Trägerschaft. Die von ihm

49 Bundesamt für Gesundheit, Statistik der obligatorischen Krankenversicherung 2007 - Tabellen und Beilagen, Tabelle 11.07.

50 Indra, SwissDRG und ihre Auswirkungen, S. 193.

51 Eugster, Grund- und zusatzversicherte Leistungen, S. 25.

52 Siehe II.5.2.

53 Siehe II.4. 
erlassene Spitalliste, die für Zahlungen der Krankenversicherer Voraussetzung ist, war auch bis zur Errichtung des Bundesverwaltungsgerichtes nicht justitiabel, sondern konnte nur durch Rekurs vor dem Kanton und letztinstanzlich vor der Regierung in Bern (Bundesrat) angegriffen werden. Nun können Beschwerden gegen die Spitalliste vor das Bundesverwaltungsgericht gebracht werden, sind also umfänglich justitiabel. ${ }^{54}$

Das Spitalangebot insgesamt wird also einerseits durch formales Recht bestimmt (Spitalliste) und andererseits durch das Faktum, das bereits jeder Kanton über eigene Spitäler verfügt. Weiterhin ist das Spitalangebot dadurch geprägt, daß dem Versicherten nur diejenigen Kosten ersetzt werden, die in seinem Heimatkanton für Leistungen bezahlt werden. Mit anderen Worten: Begibt sich der Versicherte aus seinem Heimatkanton, muß er gegebenenfalls mit Mehrkosten rechnen. Diese Mehrkosten werden zwar eventuell vom Zusatzversicherer übernommen, erschweren aber im übrigen die gesetzlich festgelegte Wahlfreiheit.

\subsubsection{Der Staat als Multiakteur}

Der Staat, zumeist der Kanton, steuert aber nicht nur das Gesundheitswesen und überwacht es. Er ist auch nicht nur ein Anbieter auf dem Markt (siehe oben). Vielmehr trägt er auch die Kosten im Gesundheitswesen weiterhin. Dies nicht nur wegen Infrastrukturmaßnahmen, wie etwa Errichtung von Kantonsspitälern oder Universitätskliniken, sondern auch bei jeder Leistung. Im Spitalwesen gibt es kein monistisches System der Leistungstragung. Vielmehr übernehmen der Versicherer und der jeweilige Kanton zusammen die Kosten für die obligatorischen Leistungen.

Schließlich trägt der Staat auch insoweit Kosten, als er die Prämien pro Versicherten verbilligt. Nach Einkommen gegliedert gibt es Prämienverbilligungen. Damit beeinflußt der Staat die Prämienkalkulation der Krankenversicherer. Der Versicherte macht die Prämienverbilligung gegenüber dem jeweiligen Kanton geltend. 55 Die Prämienverbilligung kann heute als Bedarfsleistung eingeordnet werden und nähert sich immer mehr einem Rechtsanspruch an. ${ }^{56}$ Im Jahre 2007 erhielten insgesamt 2,271 Mio. Personen eine Prämienverbilligung; diese betrug im Durchschnitt 1506 CHF. ${ }^{57}$ Die Kosten für die Prämienverbilligung werden zwischen dem Kanton und dem Bund aufgeteilt. Das System ist so vorgesehen, daß der Bund die Gelder pro Kanton nach dessen Bevölkerungszahl (1997 bis 2001 auch nach der Prämienhöhe; bis 2007 auch nach der Finanzkraft der Kantone) zahlt, wobei der Bundesbeitrag für alle Kantone insgesamt der Höhe

54 Art. 34 des Bundesgesetzes über das Bundesverwaltungsgericht vom 17. Juni 2005 (SR 173.32); BVwG, Zwischenverfügung vom 20.10.2008 (C-2907/2008).

55 Art. $65 \mathrm{KVG}$.

56 Eugster, Krankenversicherung, Rz. 1068.

57 Bundesamt für Gesundheit, Statistik der obligatorischen Krankenversicherung 2007 - Graphiken und Kommentare, S. 30-31. 
von 7,5 Prozent der Bruttokosten der obligatorischen Krankenversicherung entspricht ${ }^{58}$. Diese Art der Finanzierung folgt dem neuen ${ }^{59}$ Konzept des Finanzausgleichs zwischen Bund und Kantonen.

\subsubsection{Wettbewerb und wettbewerbliche Elemente}

Während Leistungen und Leistungsverhältnisse im Zusatzversicherungsbereich vollkommen den Wettbewerbsgesetzen unterliegen, ist das obligatorische Krankenversicherungswesen nicht durch Wettbewerbsrecht i.e.S. geprägt. Dennoch ist dieses System durch zahlreiche wettbewerbliche Elemente gekennzeichnet. So ist die Schweiz eines der ersten Länder Europas gewesen, welches HMO, Managed Care und Integrierte Versorgung im Rahmen der obligatorischen Versicherung einführte. ${ }^{60}$ Diese Wettbewerbsfelder haben sich in zunehmender Weise bis heute vergrößert: Bereits im Jahre 2002 hatte jeder 10. Einwohner der Schweiz eine Versicherung mit Integrierter Versorgung oder HMO-Modell. ${ }^{61} \mathrm{Im}$ Jahre 2007 verfügte dann schon fast jeder 4. Einwohner über eine Versicherung mit eingeschränkter Wahl des Leistungserbringers, mithin also über eine Versicherung mit Integrierter Versorgung, HMO- oder Hausarzt-Modell. ${ }^{62}$

\subsubsection{Preisbildung und Tarife}

Der Tarif zur Kostenvergütung des Leistungserbringers durch die Krankenversicherer kann nach Maßgabe des KVG wie folgt definiert werden: Der Tarif ist ein Rahmen für vertragliche Kostenpreise, die nach dem tatsächlichen oder standardisierten Aufwand des Erbringers berechnet werden. Damit sind alle Ansprüche des Erbringers gegenüber dem Empfänger abgegolten. ${ }^{63}$ Die Leistungen werden durch die zuständigen Behörden und die Versicherer nach den Kriterien der Zweckmäßigkeit, Wirksamkeit und Wirtschaftlichkeit überprüft gemäß Art. 32 i.V.m. 46 Abs. IV KVG. Je nachdem, welche Finanzierung gewählt wird, unterliegen die Spitäler positiven und negativen Anreizen: Der Einzelleistungstarif wirkt in der Regel mengentreibend, Fallpauschalen oder Globalbudgets können die implizite Abweisung von schweren Fällen zur Folge

58 Art. 66 KVG i.V.m. Verordnung über den Bundesbeitrag zur Prämienverbilligung in der Krankenversicherung vom 7. November 2007 (SR 832.112.4).

59 Zuvor mußten die Kantone ihrerseits einen Komplementärbeitrag im Umfang von 50\% des Bundesbeitrages leisten (1996 35\%, 1997 40\%, 1998 45\%, seit 1999 50\%). Der Subventionsbeitrag lag damit z.B. für 2002 bei 3.47 Mrd. CHF. Tatsächlich waren es nur 2.98 Mrd. CHF, weil die Kantone von der Reduktion Gebrauch machten. Denn die Kantone konnten ihre Beteiligung senken, wodurch allerdings auch der Bundeszuschuß sank. Hiervon machten 2002 immerhin 15 Kantone Gebrauch. Die genannten Zahlen ergeben sich aus: Bundesamt für Gesundheit, Statistik der obligatorischen Krankenversicherung 2003, S. 22.

60 Erste HMO bereits 1990 und 1991: Finsterwald, Managed Care - Pionierland Schweiz, S. 75.

61 Winkler, Integrierte Versorgung, S. 27-29.

62 Bundesamt für Gesundheit, Statistik der obligatorischen Krankenversicherung 2007 - Tabellen und Beilagen, Tabelle 11.06.

63 Sogenannter Tarifschutz, Art. 44 KVG. 
haben. ${ }^{64}$ Praktisch alle genannten Finanzierungsformen waren und sind in der Schweiz anzutreffen: 65

Einzelleistungstarif für ambulante Behandlung und Zusatzversicherer in den Spitälern;

Pauschalisierte Abgeltungen wie Tages-, Abteilungs- und Fallpauschalen (je nach

Versicherer, Kanton und Leistungsbereich);

Globalbudgets in gewissen Kantonen;

Preise für außerkantonale Patienten.

Die Teilrevision des KVG - grundsätzlich in Kraft getreten am 1. Januar 2009, allerdings mit Übergangszeiten bis in das Jahr 2014 hinein - hat unter anderem zum Ziel, daß die Vielfalt vertraglich möglicher Tarif- und Preisbildungen ihr Ende findet und nunmehr in der Regel Fallpauschalen zur Geltung kommen werden, ${ }^{66}$ die auf gesamtschweizerischen Strukturen beruhen. ${ }^{67}$ Damit soll eine Vergleichbarkeit der Kosten erreicht und somit Wettbewerb gefördert werden. Denn die bisher anzutreffende unterschiedliche Tarif- und Preisbildung in jedem Kanton bedingte geradezu signifikante Unterschiede im wirtschaftlichem Anreiz. Dem kam und kommt gleich, daß durch die insgesamt nicht-monistische Finanzierung der Leistungen 68 ein Wettbewerbsvorteil für Spitäler gegenüber anderen ambulanten Erbringern besteht. Dies ist letztlich schon deswegen der Fall, weil die Finanzierung ambulanter Leistungen außerhalb der Spitäler monistisch erfolgt, also nur durch die Versicherer, und damit die Tendenz besteht, daß an der Schnittstelle ambulanter/stationärer Medizin die volkswirtschaftlich günstigeren ambulanten Leistungen dennoch stationär ausgeführt werden, weil sie den Versicherern billiger zu stehen kommen. 69

\section{Die Krankenhausversorgung}

Das schweizerische Spitalwesen nimmt eine zentrale Rolle im Gesundheitswesen ein. ${ }^{70}$ Die Spitäler sollen nicht nur für eine flächendeckende Leistungserbringung stationärer (bis 2009 auch teilstationärer) Behandlung sorgen, sondern sie dürfen auch ambulante Leistungen erbringen und somit für diese Leistungen in Konkurrenz zu anderen Leistungserbringern treten. Daneben obliegt es einzelnen Spitälern, vor allem den Universitätsspitälern, Forschung der Spitzenmedizin zu betreiben; einer der wichtigen Voraussetzungen für ein qualitativ hochwertiges Gesundheitswesen.

64 Undritz, Krankenhaus, S. 103.

$65 \mathrm{Zu}$ den Tarifen und Tarifverträgen vgl. Kapitel II.3.1.

66 Art. 49 Abs. I S. 2 KVG.

67 Art. 49 Abs. I S. 3 KVG.

68 Der Wohnkanton und der Versicherer kommen im Grundfall für die Kosten stationärer Behandlung auf.

69 So schon Undritz, Krankenhaus, S. 103.

70 Vgl. Kapitel I.2.1. 


\subsection{Leistungen im Krankenhaussektor}

Das Konzept der Leistungserbringung im Spital nach dem KVG wird geprägt von den Begriffen der einzelnen Leistungsarten (stationär, ambulant) und von der Bestimmung, was eine Leistung nach dem KVG ist:

Die Begriffe stationäre und ambulante (bis 2009 auch teilstationäre) Behandlung finden sich zwar im KVG selbst, ihre Definition und damit die Abgrenzung zwischen den Behandlungsarten untereinander wie auch die Abgrenzung zu anderen Arten von Leistungen werden aber in der VKL ${ }^{71}$ geregelt. Dabei wird heute nur noch zwischen stationärer und ambulanter Behandlung unterschieden. Zuvor unterteilte man auch noch in teilstationäre Behandlung 72 . Diese Feinunterscheidung hat sich in der Praxis nicht bewährt. ${ }^{73}$ Nach Art. 3 VKL gelten als stationäre Behandlung Aufenthalte im Spital von mindestens 24 Stunden zur Untersuchung, Behandlung und Pflege, Aufenthalte im Spital von weniger als 24 Stunden, bei denen während einer Nacht ein Bett belegt wird, sowie Aufenthalte im Spital bei Überweisungen in ein anderes Spital und bei Todesfällen. Damit folgt die Definition nach der Rechtsprechung des EVG ${ }^{74}$ der altrechtlichen Einordnung des KUVG nun auch im KVG.

Die ambulante Behandlung wird in Art. 5 VKL damit umschrieben, daß sie jede Behandlung umfaßt, die keine stationäre Behandlung ist. Demnach gehören heute zum Begriff ambulante Behandlung all jene Behandlungsarten, die man zuvor als teilstationäre Behandlung begriff. ${ }^{75}$ Zur Abgrenzung der ambulanten Behandlung im Spital von anderen Behandlungsformen als der stationären Behandlung kann Art. 6 VKL herangezogen werden, welcher die Langzeitpflege definiert. Demnach zeichnet sich die ambulante Spitalbehandlung dadurch aus, daß ihr ein Aufenthalt im Spital zu Grunde liegt, der nach medizinischer Indikation eine Behandlung und Pflege oder eine medizinische Rehabilitation im Spital erfordert. Ist die medizinische Indikation nicht gegeben, handelt es sich jedenfalls nicht um eine ambulante Spitalbehandlung der obligatorischen Krankenversicherung.

Wenngleich die Definitionen der einzelnen Behandlungsarten geeignet sind $\mathrm{zu}$ bestimmen, um welche Art der Spitalbehandlung es sich nach dem KVG handelt, und somit weitreichende Folgen für die Ermittlung der maßgebenden Tarife und für die

71 Verordnung vom 3. Juli 2002 über die Kostenermittlung und die Leistungserfassung durch Spitäler und Pflegeheime in der Krankenversicherung (SR 832.104).

72 Als teilstationäre Behandlung galten nach Art. $4 \mathrm{aF}$ VKL geplante Aufenthalte zur Untersuchung, Behandlung und Pflege, die eine an die Behandlung anschließende Überwachung oder Pflege sowie die Benutzung eines Bettes erfordern, sowie auch wiederholte Aufenthalte in Tages- oder Nachtkliniken. Demnach grenzte sich im Umkehrschluß zu Art. 3 VKL die teilstationäre von der stationären Behandlung dadurch ab, daß der jeweilige Aufenthalt weniger als 24 Stunden dauerte oder nicht mit einer Übernachtung verbunden war. Vgl. Eugster, Krankenversicherung, Rz. 384 und 382.

73 Gächter/Vollenweider, Gesundheitsrecht, Rz. 738.

74 BGE 127 V 409.

75 Zur Definition vgl. Fn. 72. 
Kostentragung nach dem KVG haben, ist damit noch nicht geklärt, was überhaupt eine Leistung nach dem KVG ist. Denn nach den Art. $24 \mathrm{KVG}$ übernimmt die obligatorische Krankenversicherung die Kosten für Leistungen gemäß den Art. 25-31 KVG (d.h. insbesondere Diagnose und Behandlung von Krankheiten, Medizinische Prävention und besondere Leistungen bei Mutterschaft) nur, wenn diese Leistungen wirksam, zweckmäßig und wirtschaftlich sind. Die Krankenversicherer dürfen im Rahmen der obligatorischen Krankenversicherung keine anderen als die genannten Leistungen übernehmen. Zur Klärung, was eine wirksame, zweckmäßige und wirtschaftliche Leistung im Sinne des Leistungsbereiches der Art. 25-31 KVG ist, bedient sich das schweizerische System eines facettenreichen Kommissionswesens, das hier, da es nicht nur für Spitalleistungen sondern für alle Leistungen des KVG maßgebend ist, nur in groben Zügen beschrieben werden kann:

Die in Art. 33 Abs. IV KVG und Art. 37a KVV sogenannten Beratenden Kommissionen unterstützen den Verordnungsgeber bei der Erstellung von Listen, die für die Leistungserbringung nach dem KVG verbindlich sind. Ihre Zusammensetzung soll dafür sorgen, daß unter den verschiedensten Gesichtspunkten wirksame, zweckmäßige und wirtschaftliche Leistungen bestimmt werden. Die Eidgenössische Kommission für allgemeine Leistungen und Grundsatzfragen 76 berät das EDI (Eidgenössische Departement des Inneren) bei der Bezeichnung der allgemeinen Leistungen, insbesondere der Diagnose- und Behandlungsarten. Aus diesem Beratungsprozeß gehen die jeweiligen Regelungen der KLV77 und insbesondere der Negativkatalog hervor (Anlage 1 der KLV), in dem minutiös aufgelistet wird, welche Diagnose- oder Behandlungsart eine Leistung des KVG ist oder nicht, jedoch auch solche, die zur Zeit noch in Überprüfung sind. Die Eidgenössische Arzneimittelkommission 78 berät hauptsächlich das Bundesamt für Gesundheit (BAG) bei der Erstellung der Spezialitätenliste, daneben auch bei der Erstellung der Arzneimittelliste. Die Eidgenössische Kommission für Analysen, Mittel und Gegenstände ${ }^{79}$ berät das EDI bei der Erstellung der Analysenliste ${ }^{80}$ und bei

76 Zusammensetzung nach Art. 37d KVV: 20 Mitglieder werden vom Bundesrat ernannt, davon müssen vertreten: 6 Mitglieder die Ärzteschaft, 1 die Spitäler(-betreiber), 1 die Apotheker, 5 die Kranken- und Unfallversicherungen, 2 die Versicherten, 1 die Kantone, 1 die Analysen-, Mittel und Gegenständekommission, 1 die Dozenten der Laboranalytik und 2 die medizinische Ethik. Der Kommission steht ein Vertreter des BAG (Bundesamt für Gesundheit) vor.

77 Verordnung des EDI über Leistungen in der obligatorischen Krankenpflegeversicherung (SR 832.112.31).

78 Zusammensetzung nach Art. 37e KVV: 20 Mitglieder werden vom Bundesrat ernannt, davon müssen vertreten: 3 Mitglieder die Ärzteschaft, 1 die Spitäler(-betreiber), 3 die Apotheker, 3 die Kranken- und Unfallversicherungen, 2 die Versicherten, 1 die Kantone, 4 die Fakultäten der Medizin und Pharmazie, 2 die Pharmaindustrie und 1 das Schweizerische Heilmittelinstitut. Der Kommission steht ebenfalls ein Vertreter des BAG vor.

79 Zusammensetzung nach Art. 37f KVV: 19 Mitglieder werden vom Bundesrat ernannt, davon müssen vertreten: 2 Mitglieder die Ärzteschaft, 1 die Spitäler(-betreiber), 1 die Apotheker, 4 die Kranken- und Unfallversicherungen, 2 die Versicherten, 1 das Schweizerische Heilmittelinstitut, 2 die Dozenten der Laboranalytik, 2 die Laboratorien, 1 die Diagnostica- und Diagnosticageräteindustrie, 
der Beurteilung von Mitteln und Gegenständen. Aus diesem Prozeß gehen die Regelungen der KLV und insbesondere der Festlegung dieser Leistungen in Anhang 2 und 3 zur KLV hervor.

Insgesamt kann festgehalten werden, daß die Leistungen im Spital nach dem KVG einerseits reglementiert sind, insbesondere hinsichtlich der Wirksamkeit, Zweckmäßigkeit und Wirtschaftlichkeit, andererseits aber das medizinisch Notwendige beinhalten. Andere Leistungen, die nicht aufgrund des KVG getragen werden, also Mehrleistungen darstellen, müßten von den Patienten selbst oder von deren Zusatzversicherungen vergütet werden. $\mathrm{Ob}$ hierfür überhaupt Raum besteht, ist allerdings fraglich. Denn die Literatur nimmt an, ${ }^{81}$ daß es medizinisch notwendige Leistungen außerhalb des Leistungskataloges des KVG, also echte Mehrleistungen, so gut wie nicht gibt, orientiert sich das KVG doch daran, die Gesundheitsversorgung auf qualitativ hohem Niveau sicherzustellen, was vor allem durch die KLV und die Leistungskataloge erreicht wird. Dem kommt gleich, daß auch die Zusatzversicherer sich am Grundsatz der Wirksamkeit, ZweckmäBigkeit und Wirtschaftlichkeit ausrichten, so daß es in der Praxis wohl kaum Raum für von Dritten getragene Luxusbehandlungen im medizinischen Sinne gibt. Davon zu unterscheiden sind die sogenannten unechten Mehrleistungen, die vor allem in der Auswahl des behandelnden Arztes sowie im Unterkunftsservice liegen und damit keine medizinischen Mehrleistungen im engeren Sinne sind. Diese Leistungen werden in den sogenannten Halbprivat- oder Privatabteilungen der Spitäler erbracht und sind der eigentliche Gegenstand des Zusatzversicherungswesens. ${ }^{82}$

\subsection{Organisationsstruktur des Krankenhaussektors}

Was ein Spital ist, könnte vielfach gedeutet werden. Einer ökonomischen Studie über schweizerische Spitäler nach ist ein Spital ein Gebäude oder ein Gebäudekomplex, in dem Kranke aller Art durch Ärzte und Pflegepersonal von ihrer Krankheit befreit werden, wobei das Ganze von einer Organisation umfaßt wird, die es zu einem Betrieb zusammenhält. 83 Mit einer solchen Definition ist jedoch noch nicht allzuviel gewonnen, weil sie die Unterschiede etwa zu einem Ärztezentrum oder einer reinen Tagesklinik nicht deutlich hervorbringt. Hinzuzufügen wäre einer solchen Definition in jedem Falle, daß ein Spital ebenfalls Betten und Service zur Übernachtung anbieten muß. Mit

2 die Hersteller und Vertreiber von Mitteln und Gegenständen und 1 die Abgabestellen für Mittel und Gegenstände. Auch dieser Kommission steht ein Vertreter des BAG vor.

80 Mittel- und Gegenstände-Liste, Arzneimittelliste, Analysenliste und Spezialitätenliste werden nicht in der SR publiziert, können jedoch online eingesehen werden:

www.bag.admin.ch/kv/gesetze/d/index.htm.

81 Vgl. etwa Eugster, Grund- und zusatzversicherte Leistungen, S. 25.

82 Ein weiterer Gegenstand des Zusatzversicherungswesens ist die Auswahl des Spitals, insbesondere außerhalb des Wohnortkantons, insoweit das außerkantonale Spital sich nicht auf der kantonalen Spitalliste (siehe II.2.1.) befindet. Zur Auswahl des Spitals siehe II.1.

Heusser, Öffentliche und private Spitäler, S. 119. 
einer solchen Erweiterung ist man wiederum nahe am Begriff der stationären Behandlung. Und in der Tat ist der gesetzliche Spitalbegriff eng mit dem Begriff der stationären Behandlung verknüpft. Nach der Legaldefinition des Art. 39 Abs. I KVG sind Spitäler „Anstalten oder deren Abteilungen, die der stationären Behandlung akuter Krankheiten oder der stationären Durchführung von Massnahmen der medizinischen Rehabilitation dienen (Spitäler)“. Damit kommt zum Ausdruck, daß Spitäler im Sinne des KVG, obgleich sie, wie eben gezeigt ${ }^{84}$, Leistungen der ambulanten Behandlung anbieten können, in einer gesetzeskonformen Auslegung zu einem gewissen Grade sogar anbieten sollten, immer stationäre Behandlung in ihrem Leistungsangebot haben müssen. Reine Tages- oder Nachtkliniken, Geburtshäuser ohne Notfallinfrastruktur sind somit ebenso wenig Spitäler im Sinne des KVG wie etwa Einrichtungen zur Langzeitpflege, zur reinen beruflichen und/oder sozialen Rehabilitation sowie zur Kur, immer vorausgesetzt, daß sie über keinerlei Dienstleistungs- oder Infrastrukturvoraussetzungen für stationäre Behandlung und/ oder medizinischer Rehabilitation verfügen. 85

Der gesetzliche Spitalbegriff des KVG grenzt zwar Spitäler von anderen Einrichtungen ab, dennoch bedarf es weiterer Voraussetzungen, um ein Spital im Sinne des KVG zu sein. Herausragendes Kriterium hierfür ist die Notwendigkeit der Zulassung durch den jeweiligen Kanton. Wenngleich hier nicht der Ort ist, das Zulassungsverfahren zu beleuchten, ${ }^{86}$ so zeigen aber schon die Voraussetzungen der Zulassung, welche Anforderungen das KVG an ein Spital stellt, damit dessen Leistungen als Leistungen der obligatorischen Krankenversicherung gelten können: $\mathrm{Zu}$ nennen sind zunächst die Dienstleistungs- und Infrastrukturvoraussetzungen, insbesondere eine Gewährleistung der genügenden ärztlichen Betreuung nach Art. 39 Abs. I lit.a KVG, das zur Verfügung Stellen des erforderlichen Fachpersonals nach Art. 39 Abs. I lit.b KVG und die Gewährleistung zweckentsprechender medizinischer Einrichtungen und pharmazeutischer Versorgung nach Art. 39 Abs. I lit.c. KVG. Des weiteren zu nennen sind die Bedarfsdeckungs- und Koordinationsvoraussetzungen, insbesondere daß ein Spital der Spitalplanung 87 eines oder mehrerer Kantone für eine bedarfsgerechte Spitalversorgung entspricht gemäß Art. 39 Abs. I lit. d KVG. Schließlich ist die Publizitätsvoraussetzung zu erwähnen, was nichts anderes heißt, als daß ein Spital auf der nach Leistungsaufträgen in Kategorien gegliederten kantonalen Spitalliste ${ }^{88}$ gemäß Art. 39 Abs. I lit.e KVG verzeichnet sein muß.

In der Binnenorganisation der Spitäler gibt es häufig die Unterscheidung zwischen Allgemeiner Abteilung, Halbprivatabteilung und Privatabteilung. Dabei gilt als Allgemeine Abteilung diejenige, in der nur Leistungen nach dem KVG erbracht werden, während die Halbprivat- und die Privatabteilungen (auch) Leistungen außerhalb des KVG

84 Siehe I.3.1.

85 So auch Eugster, Krankenversicherung, Rz. 739.

86 Siehe aber: II.4.

87 Zur Spitalplanung siehe II.4.2.

88 Zur Spitalliste siehe II.4.2. 
erbringen, insbesondere die sogenannten unechten Mehrleistungen (etwa Arztwahl und Unterkunftsservice). Dies sind keine Unterscheidungen, die man direkt aus dem KVG entnehmen könnte. Auch läßt sich eine solche Unterscheidung, vor allem eine rechtliche Pflicht zu einer Allgemeinen Abteilung, nicht aus dem KVG ableiten. ${ }^{89}$ Dennoch spielt die Unterscheidung faktisch wie rechtlich eine bedeutsame Rolle. Sollen in der Halbprivat- oder der Privatabteilung auch Leistungen nach dem KVG erbracht werden mit der Folge, daß der Versicherte oder eventuell sein Zusatzversicherer nur die Mehrkosten für die Mehrleistungen zu tragen haben, so müssen diese Abteilungen zugelassen werden und somit sowohl die Dienstleistungs- und Infrastrukturvoraussetzungen wie auch die Bedarfsdeckungs-, Koordinations- und Publizitätsvoraussetzungen nach Art. 39 I lit.a-e erfüllen. ${ }^{90}$ Mit anderen Worten: Entsprechen die Halbprivat -oder Privatabteilungen nicht der kantonalen Spitalplanung und/oder sind sie nicht explizit als eigene Abteilungen auf der Spitalliste aufgeführt, können sie Leistungen nach dem KVG nicht erbringen und sind demnach auch keine Spitäler im Sinne des KVG.

In der rechtlichen Betrachtung gibt es über die Binnenorganisation hinaus eine wichtige Unterscheidung, nicht zu verwechseln mit dem zuvor Gesagtem, zwischen privaten Spitälern und öffentlichen bzw. öffentlich subventionierten Spitälern. Die jeweilige Einordnung spielt überall dort eine Rolle, wo die Kantone als Akteure im Gesundheitswesen auftreten: So trägt etwa der Kanton nur dann einen Zuschuß zur jeweiligen Spitalleistung, wenn der Leistungserbringer ein öffentliches bzw. öffentlich subventioniertes Spital ist. Darüber hinaus hat der Kanton bei der Spitalplanung und bei der Erstellung der Spitalliste private Spitäler nur angemessen zu berücksichtigen. Ihm wird also hinsichtlich dieser Spitäler ein Auswahlermessen eingeräumt. Dies hat weitreichenden Folgen dafür, ob eine Leistungserbringung überhaupt als Spitalleistung im Sinne des KVG angesehen wird. Im Jahr 2004 gab es in der Schweiz noch 132 private und 213 öffentliche bzw. öffentlich subventionierte Spitäler ${ }^{91}$; im Jahre 2005 waren es dann nunmehr 129 private und 208 öffentliche bzw. öffentlich subventionierte Spitäler. ${ }^{92}$ Beachtlicher als der Rückgang innerhalb eines Jahres ist der Rückgang von 1997 bis 2005 von 406 auf 337 Spitäler insgesamt. ${ }^{93}$

Das Kriterium zur Unterscheidung zwischen privaten Spitälern auf der einen Seiten und den öffentlichen bzw. öffentlich subventionierten Spitälern auf der anderen Seite ist weniger der Frage geschuldet, wer Rechtsträger oder Verantwortlicher ist oder in welcher Gesellschaftsform die Spitäler errichtet wurden oder ob sie überhaupt eine eigene Rechtspersönlichkeit haben, sondern vielmehr ist zu unterscheiden, ob die öffentliche Hand das Spital finanziell bevorteilt. Bei den echten öffentlichen Spitälern ist dies außer Frage, sind sie doch kantons- oder gemeindeeigene Spitäler bzw. von Zweckverbänden,

89 Maurer, Krankenversicherungsrecht, S. 147.

90 Eugster, Krankenversicherung, Rz. 741.

91 Bundesamt für Gesundheit, Kennzahlen der Schweizer Spitäler 2004, S. 12.

92 Bundesamt für Gesundheit, Kennzahlen der Schweizer Spitäler 2005, S. 7.

93 Ebenda, S. 6. 
zumeist von Gemeindeverbänden, betriebene oder ihnen gehörende Einrichtungen, sind sie damit Einrichtungen des Gemeinwesens ${ }^{94}$, gleichgültig wie sie verfaßt sind, und liegt somit die finanzielle Bevorteilung in der finanziellen Letztverantwortung der öffentlichen Hand als Eigentümerin oder Beteiligungsinhaberin. Fundamentaler ist die Frage, wann ein Spital als privat oder öffentlich subventioniert gilt, stehen doch hinter diesen Spitälern immer Private. Ausschlaggebendes Kriterium ist die Subvention seitens der öffentlichen Hand. Als Subventionen gelten weder die Übernahme von Investitionskosten ${ }^{95}$, einmalige Leistungen wie etwa Abtretung von Gebäuden und Grundstücken, Minderheitsbeteiligungen der öffentlichen Hand durch nicht aus Steuermitteln finanzierte Gelder, vertragliche Verpflichtungen des Kantons zur Restdefizitübernahme noch Subventionen anderer Kantone für ein Spital im eigenen Kanton. ${ }^{96}$ Entscheidend für eine Subvention sind daher nicht vertragliche oder freiwillige Leistungen, sondern nur Betriebsbeiträge nach kantonalem Recht, insbesondere wenn solche Beiträge zu den Betriebskosten im jeweiligen Gesetz des Kantons vorgesehen sind.

Weiterhin lassen sich die Spitäler in die Art ihres Angebotes unterteilen. Die Grundklassifizierung unterscheidet in Allgemeine Spitäler und Spezialspitäler. Zu ersteren gehören 28 Spitäler der Zentrumsversorgung (27/1) $)^{97}$ mit einem breiten medizinischen Angebot sowie 122 Spitäler der Grundversorgung (85/34) mit dem medizinischen Basisangebot. Zu letzteren gehören 64 Psychiatrien (51/13), 45 Rehabilitationskliniken (18/27), 40 Spezialkliniken der Chirurgie, Gynäkologie/Neantologie oder Pädiatrie (7/33) sowie 35 Spezialkliniken anderer Fachrichtungen (18/17). Wiewohl diese Bezeichnungen nicht juristischer Natur sind, haben sie dennoch insoweit rechtliche Bedeutung, als bei der Erstellung der kantonalen Spitalplanung wie auch bei der Aufstellung der kantonalen Spitallisten dafür Sorge zu tragen ist, daß der kantonalen Wohnbevölkerung ausreichend medizinisches Angebot zur Verfügung steht. Demnach finden sich diese Klassifizierungen auch teilweise in den kantonalen Normen wieder, sei es bereits in den Gesundheitsgesetzen, sei es konkret in den Spitallisten.

Schließlich unterscheiden sich die Spitäler voneinander durch ihre Verfaßtheit. Dabei spielt die Einordnung als privates Spital oder öffentliches bzw. öffentlich subventioniertes Spital keine große Rolle. Vielmehr herrscht selbst bei den öffentlichen Spitäler eine gewisse Buntheit der Verfaßtheit, seien es öffentlich-rechtliche Körperschaften oder Anstalten, gemeinnützige Aktiengesellschaften oder öffentlich-rechtliche Stiftungen, seien es Spitäler mit eigener Rechtspersönlichkeit oder ohne eigene Rechtspersönlichkeit. Bei den privaten Spitälern und den öffentlich subventionierten Spitälern herrscht die Formenfreiheit, so daß es alle Typen des Privatrechts gibt, von der Einfachen Ge-

94 Poledna/Berger, Öffentliches Gesundheitswesen, Rz. 105.

95 Entscheid des Bundesrates vom 26.3.1997, RUKV 1997 KV 2.

96 Entscheid des Bundesrates vom 29.4.1998, RUKV 1998 KV 32.

97 Die in diesem Absatz in Klammern genannten Zahlen nennen die Anzahl von öffentlichen bzw. öffentlich subventionierten Spitälern gegenüber ( / ) privaten Spitälern und beruhen auf: Bundesamt für Statistik, Spitalaufenthalte 2005, S. 7. 
sellschaft, über die $\mathrm{KG}, \mathrm{AG}$ und $\mathrm{GmbH}$ bis hin zur Genossenschaft und zur privaten Stiftung. ${ }^{98}$ Bei letzterem ist bedeutsam, daß die Privatisierung eines öffentlichen Spitals nicht automatisch zu seiner Einordnung als privates Spital führt, vielmehr kommt es auf die konkreten Umstände, insbesondere der Beteiligungshöhe, an. ${ }^{99}$ Letztlich ist die Verfaßtheit der Spitäler hinsichtlich des neuen Kartellgesetzes auch nicht mehr entscheidend für die Frage, ob es sich um ein Unternehmen handelt, weil im Gegensatz zur alten Rechtslage der formale Unternehmensbegriff durch den funktionalen Unternehmensbegriff abgelöst worden ist. 100

\subsection{Rechtlicher Rahmen}

Das gesamte Spitalwesen ist geprägt von zwei unterschiedlichen Normengefügen, die durchaus Interdependenzen aufweisen. Einerseits bestimmen das Sozial- und Privatversicherungsrecht das Recht der Leistungserbringer, Leistungsträger und Leistungsempfänger, andererseits ist das Spitalwesen als Teil des Gesundheitswesens den Regelungen des öffentlichen Gesundheitsrechtes unterworfen. Beide Normengefüge entstammen verfassungsrechtlichen Vorgaben ${ }^{101}$ und sind einzelgesetzlich verschieden aufgestellt:

Das Krankenversicherungsrecht ist Ausdruck des verfassungsrechtlichen Auftrages aus Art. 117 Bundesverfassung 102 (BV). Demnach erläßt der Bund Vorschriften über die Krankenversicherung. In der Ausgestaltung läßt die Verfassung dem Bund freie Hand. ${ }^{103}$ Explizit räumt Art. 117 Abs. II BV dem Bund die Möglichkeit ein, „die Kranken- ... versicherung allgemein oder für einzelne Bevölkerungsgruppen obligatorisch [zu] erklären“. Von dieser Gesetzgebungskompetenz, die zugleich ein Gesetzgebungsauftrag darstellt ${ }^{104}$, hat der Bund durch das KVG umfassend Gebrauch gemacht. Das KVG errichtet nicht nur ein Obligatorium für die gesamte Wohnbevölkerung der Schweiz und unterstellt die obligatorische Krankenversicherung seinen Vorschriften, sondern das KVG regelt zudem, daß sich das Zusatzversicherungswesen nach dem Privatversicherungsrecht des VVG zu richten hat. ${ }^{105}$ Damit ordnet das KVG abschließend das Recht der Krankenversicherung und zwar nicht nur der sozialen, obligatorischen Krankenversicherung sondern ebenfalls der privaten, freiwilligen Zusatzversicherungen. Für kantonale Gesetzgebung bleibt somit kein Raum, das Krankenversicherungsrecht abweichend zu regeln. Die Kantone sind jedoch Vollzugsorgane des Krankenversiche-

98 Heusser, Öffentliche und private Spitäler, S. 119-121.

99 Eugster, Krankenversicherung, Rz. 907 mit Verweis auf BR RUKV 1998 und 1997

100 Zäch/Heizmann, Markt und Marktmacht, S. 33.

101 Vgl. zur Gesundheitsverfassung insgesamt: Gächter/Vollenweider, Gesundheitsrecht, Rz. 74ff.

102 Bundesverfassung der Schweizerischen Eidgenossenschaft vom 18. April 1999 (SR 101).

103 Mader, in: Ehrenzeller/Mastronardi/Schweizer/Vallender, BV, Rz. 3 zu Art. 117.

104 Ebendort.

105 Art. 12 Abs. 3 KVG. 
rungsrechts und -wesens. Daher erlassen sie in Ausführung des KVG und der auf ihm beruhenden Verordnungen Vorschriften, wie etwa die Spitalliste, welche zum Sozialversicherungsrecht gehören.

Das Gesundheitswesen ist nur zu einem geringen Teil in der Zuständigkeit des Bundes. Nach Art. $118 \mathrm{BV}$ ist der Bund konkurrierend zuständig für den Umgang mit bestimmten Waren und Gegenständen, insbesondere von Heilmitteln, sowie für die Bekämpfung bestimmter Krankheiten und den Schutz vor ionisierenden Strahlen. Ansonsten sind die Kantone zuständig für das Gesundheitswesen. ${ }^{106}$ Dies hat sich darin niedergeschlagen, daß jeder Kanton eigene Gesundheitsgesetze und weitere Vorschriften, wie etwa Gesetze über die Patientenrechte, erlassen hat. Die Zuständigkeit für das Gesundheitswesen ist allumfassend zu verstehen und wird nur durch die Gesetzgebung des Bundes hinsichtlich des Sozialversicherungsrechtes eingeschränkt, insbesondere dadurch, daß das KVG den Kantonen die Spitalplanung und die Erstellung von Spitallisten auferlegt und somit in ein wesentliches Element der kantonalen Autonomie im Gesundheitswesen eingreift; aber ebenso dadurch, daß der Bund nach Art. 39 Abs. 2ter KVG ermächtigt wird, für die Spitäler Planungskriterien auf der Grundlage von Qualität und Wirtschaftlichkeit zu erlassen. Das Recht des Gesundheitswesen beinhaltet vor allem Vorschriften über die Zulassung von Medizinalpersonen ${ }^{107}$, Apotheken, die Organisation von Gesundheitseinrichtungen, Regeln zur Vorsorge und Prävention sowie die Gewährleistung der Gesundheitsversorgung. Letzteres ist vor allem für das Spitalwesen wichtig, weil, abgesehen von der Spitalplanung und den Spitallisten, die aufgrund des KVG erfolgen, die Einrichtung kantonaler Spitäler, die Aufgabenzuweisung an Spitäler und die Bezuschussungsmöglichkeiten für Spitäler hier ihren Niederschlag finden.

\subsection{Beziehung zwischen Patient, Leistungsträger und-erbringer}

Die Beziehung des Versicherten zu seiner obligatorischen Krankenversicherung ist aufgrund des KVG sozialversicherungsrechtlich und damit öffentlich-rechtlich geprägt, während das Verhältnis des Versicherten zu seiner Zusatzversicherung aufgrund des KVG mit dessen Verweis auf das VVG privatrechtlicher Natur ist.

Die Beziehung des Patienten zum Spital ist je nach Art des Spitals unterschiedlich. Das Rechtsverhältnis zu den öffentlichen Spitälern ist öffentlich-rechtlich, dasjenige zu den privaten Spitälern ist privatrechtlich. ${ }^{108}$ Dennoch gibt es einzelne Aspekte, die auf-

106 Poledna, Gesundheitsrecht und Wettbewerb, S. 33; Mader, in: Ehrenzeller/Mastronardi/Schweizer/Vallender, BV, Rz. 3 zu Art. 118.

107 Die Kompetenz über Ausbildungsregeln hingegen unterliegen dem Bund aufgrund Art. 95 BV (Privatwirtschaftliche Erwerbstätigkeit). Demgemäß hat der Bund ein Medizinalberufegesetz (Bundesgesetz über die universitären Medizinalberufe vom 23. Juni 2006, SR 811.11) erlassen, mit dem er vor allem die Qualität der universitären Ausbildung, der beruflichen Weiterbildung und der Fortbildung sowie der Berufsausübung der Fachpersonen im Bereich der Humanmedizin regelt. Vgl. zu diesem Gesetz: Gächter/Vollenweider, Gesundheitsrecht, Rz. 423ff. 
grund des KVG anders einzuordnen sind. So ist etwa die Kostenschuldnerschaft des Patienten gegenüber dem Spital aufgrund des Art. 41 KVG immer privatrechtlicher Natur, gleich ob nach dem Kostenerstattungsprinzip oder nach dem Naturalleistungsprinzip zu verfahren ist. 109

Da prinzipiell das Kostenerstattungsprinzip gilt, treten die obligatorische Krankenversicherung und die Spitäler in keinerlei Verhältnis zueinander. Allerdings gibt das KVG verschiede Bereiche vor, in denen beide miteinander Vereinbarungen schließen, wie etwa beim Tarifvertrag. Die daraus entstehenden Rechtsverhältnisse sind immer sozialversicherungsrechtlicher Art und damit öffentlich-rechtlich. Ansonsten treten sich beide als Private gegenüber. Dies gilt grundsätzlich immer auch für das Verhältnis von Spitälern zu den Zusatzversicherern, gleichgültig ob der Zusatzversicherer ansonsten auch als obligatorische Krankenversicherung auftritt.

\section{Wettbewerb und Gesundheitsversorgung}

\subsection{Verfassungsrechtliche Fundierung}

Der Wettbewerb ist Ausdruck der wirtschaftlichen Freiheit. Er ist gemäß des Art. 27 Bundesverfassung (BV), in dem das Recht auf wirtschaftliche Freiheit gewährleistet wird, sowohl ein Individualanspruch als auch ein Ordnungsprinzip. ${ }^{110}$ Träger des Individualanspruches können nur Private sein, nicht jedoch das Gemeinwesen (Bund, Kantone, Gemeinden etc.), egal in welcher Ausprägung. ${ }^{111}$ Gemäß Art. 94 BV verpflichten sich der Bund und die Kantone zur Wahrung der Wirtschaftsfreiheit und zu seiner Förderung. Hierzu gehört auch, daß der Staat sich aufgrund des Gleichbehandlungsgrundsatzes in Verbindung mit Art. 94 Abs. I BV wettbewerbsneutral zu verhalten hat. ${ }^{112}$ Dennoch läßt schon Art. 94 Abs. IV BV Maßnahmen gegen den Wettbewerb unter strengen Voraussetzungen zu. Die Wettbewerbspolitik ist in einem eigenen Verfassungsartikel verankert: Nach Art. 96 BV erläßt der Bund „Vorschriften gegen volkswirtschaftlich oder sozial schädliche Auswirkungen von Kartellen und anderen Wettbewerbsbeschränkungen. Er trifft Maßnahmen ... zur Verhinderung von Missbräuchen in der Preisbildung von marktmächtigen Unternehmen des privaten und öffentlichen Rechts, ...“. Die Gewährleistung der Wettbewerbsfreiheit und den Schutz vor Beschränkungen und Mißbräuchen hat der Bund aufgrund des Verfassungsauftrages in Einzelgesetzen zum Gegenstand seiner Gesetzgebung gemacht:

109 Eugster, Krankenversicherung, Rz. 986ff.

110 Vallender, in: Ehrenzeller/Mastronardi/Schweizer/Vallender, BV, Rz. 3 zu Art. 27.

111 Ebenda, Rz. 32 zu Art. 27.

112 Ebenda, Rz. 6 zu Art. 94. 


\subsection{Wettbewerbsrechtlicher Rahmen}

Für unsere Themenstellung von herausragender Bedeutung sind die bundesstaatlichen Gesetze des Kartellgesetzes ${ }^{113}$ und des Preisüberwachungsgesetzes ${ }^{114}$. Keine Relevanz haben hingegen die Vorschriften über das Vergaberecht, weil das schweizerische Binnenmarktgesetz ${ }^{115}$, nicht zuletzt auf dem EU-Schweiz-Abkommen und den GATT-Regelungen fußend, öffentliche Güter von der Anwendung größtenteils 116 ausschließt. Auch kantonale Vergabenormen agieren in diesem Sinne. Darüber hinaus kennt die Schweiz, abgesehen von Haushaltsgesetzen, kein eigentliches Beihilferecht: Im Verhältnis zur EU gilt inhaltlich immer noch das Freizügigkeitsabkommen von 1972,117 wodurch die Anwendbarkeit des Art. 87 EUV grundsätzlich nicht gegeben ist. 118

Das Kartellgesetz (KG) ist von weitreichender Bedeutung, weil sich seit seiner Novellierung der Unternehmensbegriff fundamental geändert hat. Nicht zuletzt der indirekte Einfluß des EU-Rechtes hat dafür gesorgt, daß vom formalen Unternehmensbegriff Abstand genommen wurde und der funktionale Unternehmensbegriff Einzug gehalten hat. ${ }^{119}$ Demnach sind heute sowohl öffentliche Spitäler als auch die sozialen Krankenversicherungen Unternehmen im Sinne des KG. ${ }^{120}$ Das KG kennt insgesamt 3 Bereiche von wettbewerbswidrigem Verhalten marktbeherrschender Unternehmen. Einmal unzulässige Wettbewerbsabreden nach Art. $5 \mathrm{KG}$, des weiteren unzulässige Verhaltensweisen nach Art. $7 \mathrm{KG}$ und schließlich Unternehmenszusammenschlüsse als solche nach Art. 9 ff KG.

Die Anwendbarkeit des KG setzt voraus, daß gemäß Art. 3 Abs. I lit.a KG nicht andere Vorschriften den Wettbewerb ausschließen. Dabei spricht man von vorbehaltenen Vorschriften. Dies bedeutet aber nicht, daß ganze Regelungswerke nun automatisch die Anwendbarkeit ausschließen könnten. Im hiesigen Fall heißt dies, daß weder das KVG und seine Verordnungen noch die kantonalen Gesundheitsgesetze und Normen zum Gesundheitswesen die Anwendbarkeit des KG von vornherein ausschließen können. Denn die Anwendungsvorbehalte sind restriktiv auszulegen, solange eine gesetzliche

113 Bundesgesetz vom 6. Oktober 1995 über Kartelle und andere Wettbewerbsbeschränkungen (SR 251).

114 Preisüberwachungsgesetz vom 20. Dezember 1985 (SR 942.20).

115 Bundesgesetz vom 6. Oktober 1995 über den Binnenmarkt (SR 943.02).

116 Vgl. aber für ausgewählte Wirtschaftssektoren und ausgewählte öffentliche Güter: Abkommen zwischen der Schweizerischen Eidgenossenschaft und der Europäischen Gemeinschaft über bestimmte Aspekte des öffentlichen Beschaffungswesens vom 21. Juni 1999 (SR 0.172.052.68).

117 Seitz, Neuere Entwicklungen im Beihilferecht, S. 212.

118 Begrenzte Bereiche sind aber auszumachen, so etwa beim Luftverkehr. Vgl. Seitz, Neuere Entwicklungen im Beihilferecht, S. 212

119 Zäch/Heizmann, Markt und Marktmacht, S. 33.

120 Schaller/Tagman, Kartellrecht und öffentliches Recht, S. 707. 
Regelung noch Raum für wettbewerbliche Prinzipien zuläßt. ${ }^{121}$ Es ist also immer konkret im Einzelfall anhand der jeweiligen Norm auszulegen, ob der Gesetzgeber wettbewerbswidriges Verhalten unter Vorbehalt gestellt hat. ${ }^{122}$ Solche Vorbehalte können nicht nur durch Normen des Bundes, sondern auch durch Normen der Kantone veranlaßt werden. ${ }^{123}$ Auf die Frage, inwieweit in den einzelnen Märkten Bundes- oder kantonale Vorbehalte die Anwendbarkeit ausschließen, wird in Teil II eingegangen.

Der Frage nach Wettbewerbsverstößen nach dem KG geht die Wettbewerbskommission nach. Sie wird entweder tätig auf Antrag oder durch eigene Initiative. Ihr zur Seite steht das Sekretariat, das einen Großteil der Untersuchungen und Ermittlungen durchführt. Das Verfahren wird nach dem Verwaltungsverfahrensgesetz (VwVG) durchgeführt. Rechtsmittel gegen Entscheidungen der Wettbewerbskommission gehen an das neue Bundesverwaltungsgericht.

Das Preisüberwachungsgesetz (PüG) hat eine andere Zielrichtung als das KG. Hier geht es um den Mißbrauch in der Preisbildung. Für unsere Themenstellung von herausragender Bedeutung ist der Art. 14 PüG. Demnach ist bei behördlich zu genehmigenden oder festzusetzenden Preiserhöhungen immer der Preisüberwacher anzuhören. Er kann die Senkung des Preises beantragen oder den Verzicht auf die Erhöhung. Will die Behörde hiervon abweichen, hat sie dies ausführlich zu begründen. Im KVG gibt es zahlreiche Beispiele von Genehmigungen seitens der Behörden. $\mathrm{Zu}$ denken sind an die Tarifgenehmigungen seitens der Kantone oder etwa an die Prämiengenehmigungen durch das Bundesamt für Sozialversicherung.

Das PüG hat eine eigene Wettbewerbsbehörde, den sogenannten Preisüberwacher. Auch er ist ein unabhängiges Organ und die Verfahren richten sich ebenfalls nach dem VwVG.

\subsection{Wettbewerb im Gesundheitswesen}

Das KVG, wie schon zum wiederholten Male erwähnt, kennt zahlreiche Wettbewerbselemente. Sie zu fördern und Wettbewerbseinschränkungen zu verhindern, ist Gegenstand zahlreicher Normen, die im weiteren Verlauf des Teils II erläutert werden. Dabei darf insgesamt nicht vergessen werden, daß der Gesetzgebungsprozeß zum neuen KVG in einem nicht unbedeutenden Maße von der Wettbewerbskommission beeinflußt worden ist. ${ }^{124}$ Dennoch wird man anhand einzelner Beispiele auch zur Kenntnis nehmen müssen, daß gerade das KVG auch zahlreiche Wettbewerbseinschränkungen zum Gegenstand hat.

121 ReKo RPW 2004, 861.

122 Borer, KG, Rz. 3-5 zu Art.3.

123 BG RPW 2004, 941.

124 Lauterburg, Kartellrechtliche Fragen, S. 103. 


\section{Märkte - Wettbewerb und Regulierung in der Krankenhausversorgung}

\section{Verbraucherorientierte Anreize der Krankenhauswahl}

\subsection{Obligatorische Krankenversicherung}

\subsubsection{Recht auf Behandlung}

Es besteht kein allgemeines Recht auf Behandlung durch ein Spital. Die Standesordnung der Ärzte deklariert die Freiheit, den Behandelnden aussuchen zu können. ${ }^{125}$ Selbst die maßgebenden Kantonsgesetze sehen teilweise diese Freiheit vor. ${ }^{126}$ Darüber hinaus wird sogar die Pflicht postuliert Patienten abzulehnen, vor allem wenn fachliche Gründe zur Abweisung führen müssen. ${ }^{127}$ Trotz alle dem wird die Freiheit der Patientenwahl in zahlreichen Fällen durchbrochen und somit ein Recht auf Behandlung indiziert:

In Notfällen besteht ein Recht auf Behandlung. Die kantonalen Gesundheitsgesetze verpflichten die Leistungserbringer zum Tätigwerden, gleichgültig ob sie öffentlichrechtlich oder privatrechtlich tätig werden. ${ }^{128}$ Diese Pflicht wird durch weitere Normen bestimmt. So handelt es sich beim Unterlassen gebotener Hilfeleistung um ein zivilrechtliches Delikt ${ }^{129}$ und wird strafrechtlich, vor allem durch Art. 128 StGB, geahndet. Darüber hinaus verpflichtet die Bundesverfassung aufgrund ihres Art. 12 die öffentlichen Spitäler als Einrichtungen des Gemeinwesens direkt zur Hilfe in Notlagen. ${ }^{130}$

Schließlich sehen alle kantonalen Gesundheitsgesetze eine allgemeine Behandlungspflicht, also nicht nur in Notfällen, für die öffentlichen Spitäler vor. ${ }^{131}$ In einigen Kantonen gilt dies auch für die öffentlich-subventionierten Spitäler oder für solche, die staatlicherseits in sonstiger Weise unterstützt werden. 132

Endlich ist noch zu nennen, daß im KVG selbst seit 1. Januar 2009 eine Aufnahmepflicht postuliert wird. In Art. 41a Abs. 1 KVG heißt es: „Im Rahmen ihrer Leistungsaufträge und ihrer Kapazitäten sind die Listenspitäler verpflichtet, für alle versicherten Personen mit Wohnsitz im Standortkanton des Listenspitals eine Aufnahmebereitschaft

$125 \S 5$ der Standesordnung der FMH (Féderation de médecins suisse), online abrufbar unter: http://www.fmh.ch/de/data/pdf/standesordnung_2008.pdf

126 So etwa Art. 84 GesG FR oder Art. 30 GesG VD.

127 Poledna/Berger, Öffentliches Gesundheitsrecht, Rz. 117.

128 So etwa $\S 12$ GesG ZH, § 28 GesG LU oder $\S 25$ GesG ZG.

129 Poledna/Berger, Öffentliches Gesundheitsrecht, Rz. 122.

130 Zur verfassungsrechtlichen Frage, was damit denn inhaltlich garantiert wird bzw. ob alle medizinischen Leistungen des KVG von einem solchen Recht umfaßt werden, vgl. Gächter/Vollenweider, Gesundheitsrecht, S. 38.

131 So etwa $\S 33$ GesG ZH, § 64 GesG LU oder $\S 33$ GesG SG.

132 Poledna/Berger, Öffentliches Gesundheitsrecht, Rz. 118. 
zu gewährleisten (Aufnahmepflicht).“ Für Personen mit Wohnsitz außerhalb des Standortkantons gilt die genannte Aufnahmepflicht gemäß Art. 41a Abs. 2 KVG nur aufgrund von Leistungsaufträgen ihres Heimatkantons an besagtes Spital oder aber in Notfällen. Die Einhaltung der Aufnahmepflicht untersteht gemäß Art. 41a Abs. 3 KVG der Aufsicht der Kantone.

\subsubsection{Auswahl und Kostendeckung}

Unbeachtlich des Themas der Behandlungspflicht seitens der Spitäler ist der Patient grundsätzlich frei in der Wahl des Spitals. Dies ergibt sich schon aus dem Selbstbestimmungsrecht des Patienten. Es leitet sich hinsichtlich öffentlicher Spitäler direkt aus dem Recht der persönlichen Freiheit aufgrund von Art. 10 BV und hinsichtlich privater Spitäler aus dem Persönlichkeitsschutz nach Art. 28 ZGB ab.

Dessen ungeachtet erfährt die Wahlfreiheit nicht nur ihre Relativierung in den Rechten und (Nicht)Pflichten der Spitäler zur Behandlung, sondern im besonderen Maße in finanzieller Hinsicht: Der Patient als Versicherter nach dem KVG erhält nur diejenigen Kosten der Spitalbehandlung durch den Versicherer ersetzt, welche im KVG als Pflichtleistungen des Leistungskataloges anfallen. ${ }^{133}$ Mehrleistungen sind ihm nicht zu erstatten. Als Mehrleistungen in diesem Sinne gelten dabei nicht nur sogenannte Luxusbehandlungen wie etwa der medizinisch nichtindizierten plastischen Chirurgie, auch nicht nur unechte Mehrleistungen wie etwa Unterkunftsservice oder Chefarztbehandlung, sondern ebenfalls Leistungen von solchen Spitälern, welche auf keiner der kantonalen Spitallisten aufgeführt sind, weil diese somit grundsätzlich keine Spitalleistungen nach den KVG erbringen können. 134

Darüber hinaus ist aber die Kostendeckung seitens der Versicherer bzw. des Kantons nach dem KVG bei Inanspruchnahme stationärer Leistungen eines auf einer der kantonalen Spitallisten aufgeführten Spitals nicht in jedem Falle gleich. Denn auch bei Pflichtleistungen des KVG werden die Art und der Umfang der Kostentragung danach beurteilt, ob ein innerkantonales oder ein außerkantonales Spital die Leistung erbringt. Der nun neu eingefügte und bis zum 31. Dezember 2011 umzusetzende Art. 41 Abs. 1 bis KVG besagt auch hierbei nichts anderes. Er gewährt zwar zunächst, daß der Versicherte unter allen Spitälern wählen darf, welche sich auf irgendeiner kantonalen Spitalliste befinden; dennoch besagt dieses Wahlrecht noch nichts darüber, ob alle anfallenden Kosten übernommen werden. Vielmehr kann nach Art. 41 KVG als Faustregel gelten, daß die Kosten für Leistungen eines innerkantonalen Spitals komplett übernommen werden, während Leistungen eines außerkantonalen Spitals nur in der Höhe desjenigen Tarifes übernommen werden, der ortsüblich am Wohnortkanton des Versicherten ist. ${ }^{135}$ Ein innerkantonales Spital ist nur ein solches, das im Wohnortkanton liegt und sich auf

133 Zur Bestimmung der Leistungen nach dem KVG siehe I.3.1.

134 Siehe I.3.2. und II.4.

135 Poledna/Berger, Öffentliches Gesundheitsrecht, Rz. 513. 
der kantonalen Spitalliste des Wohnortkantons befindet. Fehlt einer dieser Voraussetzungen, wird das Spital als außerkantonales behandelt mit weitreichenden Folgen für die Kostenübernahme:

Mußte bis zum 31. Dezember 2008 ein Versicherter aus medizinischen Gründen ${ }^{136}$ ein außerkantonales öffentliches oder öffentlich subventioniertes Spital aufsuchen, so übernahm sein Kanton nach Art. 41 Abs. III aF KVG die Differenz zwischen der in Rechnung gestellten Kosten und dem ortüblichen Tarif des Wohnortkantons. Für den Fall, daß der Versicherte ein privates außerkantonales Spital aus medizinischen Gründen aufsuchen mußte, sah das Gesetz keine ausdrückliche Regelung vor. Man mußte jedoch aufgrund des klaren Wortlautes von Art. 41 Abs. III aF KVG davon ausgehen, daß eine Pflicht der Kostendifferenzübernahme durch den Kanton ausgeschlossen war. ${ }^{137}$ Ganz anders lag der Fall, wenn sich der Versicherte in einem außerkantonalen Spital auf einer Halbprivat- oder Privatabteilung eines öffentlichen oder öffentlich subventionierten Spitals behandeln ließ. Hier hatte der Kanton nach der Rechtsprechung diejenigen Kosten zu übernehmen, die er bei der Behandlung in einer Allgemeinen Abteilung hätte zahlen müssen. ${ }^{138}$

Muß nun (seit 1. Januar 2009) ein Versicherter aus medizinischen Gründen ${ }^{139}$ ein außerkantonales Spital aufsuchen, macht es gemäß Art. 41 Abs. 3 nF KVG hinsichtlich der Kostenübernahme keinen Unterschied mehr, ob das Spital als öffentliches, öffentlich subventioniertes oder privates eingestuft wird. Außer in Notfällen muß allerdings die außerkantonale Behandlung aus medizinischen Gründen vom Wohnkanton genehmigt werden. Sucht der Versicherte aus anderen Gründen ein außerkantonales Spital auf, so trägt der Versicherer aus dem a.e.c. des Art. 41 Abs. I und III KVG wiederum nur die Kosten nach dem ortsüblichen Tarif des Wohnortkantons und der Kanton selbst übernimmt keinerlei Kostendifferenz.

Insgesamt befindet sich die Wahlfreiheit des Versicherten in starker Abhängigkeit zur Kostenübernahme. Denn insoweit weder der Versicherer noch der eigene Kanton für Mehrkosten aufkommen, muß der Patient diese selbst tragen. Hierbei kann sich der Patient auch nicht auf die Einschätzung seiner Versicherung verlassen, weil dem Kanton ein eigenes Prüfungsrecht zukommt. ${ }^{140}$ Dies ist vor allem in den Fällen erheblich, wo dem Versicherten die Wahl des außerkantonalen Spitals aus medizinischen Gründen dadurch eingeengt wird, daß er selbst dafür zu sorgen hat, daß ein zweckmäßiges Spital aufgesucht wird, was unter Umständen danach zu beurteilen ist, ob der Kanton direkt

136 Zur Kasuistik vgl. Eugster, Krankenversicherung, Rz. 963-967.

137 Eugster, Krankenversicherung, Fn. 1498.

138 BGE 123 V 290.

139 Gemäß Art. 41 Abs. 3bis nF KVG liegen medizinische Gründe dann vor, wenn es sich um einen Notfall handelt oder wenn die stationäre Behandlung in den auf der Spitalliste des Wohnkantons aufgeführten Spitäler nicht erbracht wird.

140 Eugster, Krankenversicherung, Rz. 968. 
oder auf interkantonaler Ebene Vereinbarungen über die Entschädigung außerkantonaler Leistungen abgeschlossen hat. ${ }^{141}$

\subsubsection{Auswahl und Einweisung}

Der Versicherte muß sich nach dem neuen KVG nicht von einem niedergelassenen Arzt einweisen lassen. Vielmehr entspricht es seiner grundsätzlichen Wahlfreiheit, daß er ein Spital selbst aufsuchen kann. Der zuständige Spitalarzt prüft dann die Aufnahme ins Spital. ${ }^{142}$ Damit kann es geschehen, daß der Versicherte eine Leistung in Anspruch nimmt, die ihm im nachhinein nicht rückerstattet wird, sei es von der Versicherung, sei es vom Kanton. Gegenüber beiden kann der Versicherte in ein Abklärungsverfahren treten, um Gewißheit über die Kostendeckung zu erzielen. Insoweit er das Spital besucht nach Einweisung durch einen Arzt, zum Beispiel einem Belegarzt, oder durch Aufnahme durch den Spitalarzt und im Nachhinein Kosten nicht nach dem KVG übernommen werden, kann er die entstandenen Kosten eventuell aufgrund von Haftungstatbestände gegenüber dem Arzt oder dem Spital einfordern. ${ }^{143}$

\subsubsection{Auswahl und Aufklärungspflicht}

Die grundsätzliche Auswahlfreiheit für den Versicherten ist, wie eben gezeigt, mit einem gewissen Kostenrisiko verbunden. Damit er hinsichtlich seines Selbstbestimmungsrechtes überhaupt eine Entscheidung treffen kann, müssen ihm die Behandlung und ihre Folgen erklärt werden. Demnach hat der Patient einen Anspruch auf Aufklärung, das Spital eine Pflicht zur Aufklärung. Gegenüber öffentlichen Spitälern ergibt sich dies schon aus Art. 10 Bundesverfassung und aus den kantonalen Vorschriften 144; gegenüber den anderen Spitälern aus der Informations- und Rechenschaftspflicht des Beauftragten nach Art. 400 Abs. I OR ${ }^{145}$. Des weiteren ergibt sich diese Pflicht schon aus der Standesordnung. ${ }^{146}$ Wesentlich ist bei alle dem, daß der Patient neben den Informationen zur Behandlung auch über die Kosten aufgeklärt wird, vor allem wie diese zu tragen sind. ${ }^{147}$ Nur hierdurch kann es dem Versicherten überhaupt gelingen, die finanziellen Folgen der Behandlung einzuschätzen. Dies ist wiederum bedeutsam für eventuelle Ansprüche gegenüber den Aufklärungspflichtigen hinsichtlich entstandener Kosten, die nicht von Dritten übernommen werden.

141 Eugster, Krankenversicherung, Rz. 969. Ob dies seit dem 1. Januar 2009 aufgrund der Neufassung des Art. $41 \mathrm{KVG}$ grundsätzlich noch so gelten kann, muß als fraglich erscheinen.

142 Eugster, Krankenversicherung, Rz. 341 und Fn. 513.

143 Poldena/Berger, Öffentliches Gesundheitsrecht, Rz. 181-207.

144 So etwa $\S 12$ PRV ZH, § 31 GesG SO, § 21 GesG VD oder $\S 47$ GesG FR.

145 Bundesgesetz betreffend die Ergänzung des Schweizerischen Zivilgesetzbuches (Fünfter Teil: Obligationenrecht) vom 30. März 1911 (SR 220).

146 Art. 10 der Standesordnung der FMH (Féderation de médecins suisse), online abrufbar unter: http://www.fmh.ch/de/data/pdf/standesordnung_2008.pdf

147 Poledna/Berger, Öffentliches Gesundheitsrecht, Rz. 133. 
Die Aufklärungspflicht seitens des Spitals spielt aber in gleicher Hinsicht eine Rolle, wo es um die Behandlung als solche geht. Sie beinhaltet auch das Aufzeigen von Alternativen zur Behandlung, nicht nur von Alternativen der stationären sondern im besonderen von Alternativen zur stationären Behandlung. Deswegen führen kantonale Patientengesetze insbesondere die Aufklärungspflicht hinsichtlich von Alternativbehandlungen auf. ${ }^{148}$ Auch hier geht es neben den medizinischen Gründen vor allem wiederum um die Kostenfolgen.

\subsubsection{Auswahl und Information}

Der Patient würde um so besser gestellt, als es ihm schon im Vorfeld gelänge, Informationen über die Leistungen des Spitals zu erhalten, insbesondere in Bezug auf die Qualität. Es ist daher nicht verwunderlich, daß Forderungen aufkommen, die Spitäler zur Publikation von Qualitätsberichten zu verpflichten. ${ }^{149}$ Denn zur Zeit sind die Leistungserbringer aufgrund von Art. 58 KVG und Art. $77 \mathrm{KVV}$ nur verpflichtet, Qualitätsberichte und andere Informationen zur qualitativen Gesundheitsleistungen den zuständigen Behörden zu übermitteln. Diese werden aber nicht veröffentlicht. Daher ist es den Versicherten bis heute nicht möglich, Vergleiche anzustellen und damit ihre Auswahl anhand von Qualitätsmerkmalen zu treffen.

\subsubsection{Auswahl und Zugang}

Trotz der geschilderten Zugangsbegrenzungen zeichnet sich das schweizerische Spitalwesen durch eine große Verfügbarkeit von Ressourcen aus. Nicht nur die Anzahl der Spitäler pro Einwohner spricht dafür, sondern auch der regionale Zuschnitt. Dabei gibt es zwar Unterschiede in der regionalen Verteilung, vor allen Dingen die Großräume verfügen über eine große Anzahl von Spitälern, während in der Peripherie die Anzahl deutlich geringer ist; doch sind es drei wesentliche Aspekte die dies wiederum ausgleichen: Die Entfernungen innerhalb der Schweiz wie auch innerhalb der Kantone sind nicht derart ausgeprägt, als daß man nicht innerhalb weniger Stunden von einem Ort zum anderen gelangen könnte. Weiterhin verfügt schon jeder Kanton über mindestens ein öffentliches Spital. Schließlich haben in fast allen kantonalen Spitallisten außerkantonale Spitäler Eingang gefunden ${ }^{150}$, dies nicht zuletzt, um den Auftrag des KVG, für eine qualitativ hochwertige Medizin für jedermann zu sorgen, gerecht zu werden. Durch die Aufnahme in die Spitallisten sind für die Versicherten auch solche Spezialleistungen verfügbar, über die im eigenen Kanton nicht verfügt wird. Dem kommt letztlich gleich, daß seit dem 1. Januar 2009 die Kantone verpflichtet sind, im Bereich der hochspezialisierten Medizin eine gesamtschweizerische Planung für die Spitäler zu beschließen;151

148 So etwa $\S 13$ PRV ZH.

149 Locher, Die Vertreibung aus dem Schlaraffenland, S. 107-113.

150 Vgl. Spitallisten AR, ZH, TG, SG, BE.

151 Art. 39 Abs. 2bis KVG. 
was nichts anderes heißt, als daß gerade der Zugang zur hochspezialisierten Medizin kantonsübergreifend und damit schweizweit zu gewährleisten ist.

\subsubsection{Eingeschränkte Auswahl aufgrund des Versicherungsverhältnisses}

In der obligatorischen Krankenversicherung gibt es besondere Versicherungsverhältnisse, die dem Patienten eine Vergünstigung einräumen, wenn er bei der Auswahl des Leistungserbringers nicht vollkommen frei agiert. ${ }^{152}$ Insbesondere zu nennen sind hierbei die Hausarztmodelle und die HMO-Modelle. Grundsätzlich dürfen solche Modelle weder zur Leistungserweiterung 153 noch zur Leistungseinschränkung führen. ${ }^{154}$ Vielmehr gilt der Leistungskatalog der sozialen Krankenversicherung auch hier.

Die Hausarztmodelle beinhalten die vorherige obligatorische Konsultation eines Allgemeinpraktikers. Dieser hat die Funktion eines gatekeepers. Er ist die erste Anlaufstelle für alle medizinischen Leistungen. Der Hausarzt behandelt selbst oder überweist an Spezialisten oder Spitäler. Der Versicherte muß immer zuerst zu ihm, außer in Notfällen. Sucht der Versicherte selbst ein Spital auf, ohne den gatekeeper aufgesucht zu haben, verliert er den Leistungsanspruch gegenüber seiner Versicherung, auch wenn es im nachhinein medizinisch begründbar ist. ${ }^{155}$

Die HMO-Modelle beinhalten, daß der Versicherte sich verpflichtet, sich von den Leistungserbringern der HMO untersuchen und behandeln oder sich von diesen an andere überweisen zu lassen. Auch hier sind es Notfälle, die eine Ausnahme bilden. Die Leistungserbringer einer HMO haben eine Behandlungspflicht gegenüber dem Patienten. Andererseits müssen die Patienten Leistungen von den HMO entgegennehmen. Allerdings kann bestimmt werden, daß unter bestimmten Umständen der Wechsel zu einem anderen Leistungserbringer möglich ist. 156

HMO haben den Vorteil, daß der Versicherte einen Naturalleistungsanspruch gegenüber der Versicherung hat, er also nicht in Vorleistung treten muß. Darüber hinaus und mit letzterem eng verbunden sind die Handlungen der Hausärzte oder der HMO den Versicherungen zuzurechnen. ${ }^{157}$ Daher liegt ein weitere Vorteil darin, daß die Überweisung in ein Spital gleichzusetzen ist mit der Genehmigung seitens der Versicherung. Kostenrisiken, wie oben geschildert, ${ }^{158}$ verschieben sich damit im Innenverhältnis zwischen Versicherung und Versichertem zu Lasten der Versicherung.

Schließlich gibt es noch die Versicherungsmodelle mit einer Ärzteliste (Preferred Provider Organization). Hierbei geht es nicht um das gatekeeping und/oder das Zusammenwirken vieler Leistungserbringer in einem Behandlungsprozeß, sondern vielmehr

152 Siehe II.2.1.4.

153 Art. 34 Abs. 1 KVG.

154 Art. 41 Abs. 4 KVG.

155 EVG RUKV 2000 KV 108, EVG RKUV 2003 KV 241.

156 Eugster, Krankenversicherung, Rz. 1088.

157 Ebenda, Rz. 1090.

158 Siehe II.1.1.2. 
um die Einschränkung der Auswahl insgesamt. Der Versicherte kann jeden Leistungserbringer, der sich auf der Liste befindet, ohne vorherige Konsultation aufsuchen. Andere Leistungserbringer sind ihm aber grundsätzlich verwehrt. ${ }^{159}$

Verweigert ein Hausarzt eine Überweisung in ein Spital, sieht eine HMO eine Spitalbehandlung nicht als notwendig an oder gibt es auf der Ärzteliste nach Ansicht des Patienten keinen Leistungserbringer, der die medizinisch notwendige Behandlung durchführen kann, ist die Aufnahme in ein (anderes) Spital mit einem erheblichen Kostenrisiko für den Versicherten verbunden. Da alle Handlungen und Unterlassungen der vorgenannten Modelle den Versicherungen zugeschrieben werden, kann der Versicherte hiergegen Rechtsmittel einlegen. ${ }^{160}$ Bei Obsiegen wären die Kosten der Spitalbehandlung zu übernehmen.

Letztendlich und eng verbunden mit den Ausführungen in II.1.1.2. können faktische Einschränkungen dadurch geschehen, daß der Versicherte eine Zusatzversicherung abschließt, deren Leistungen ihm nur zu Gute kommen, wenn er sich an die Vorgaben der Auswahl von Leistungserbringern hält. Denn die Zusatzversicherungen werden nicht nur hinsichtlich der sogenannten unechten Mehrleistungen ${ }^{161}$ abgeschlossen, so daß besserer Unterkunftsservice oder Chefarztauswahl oder Kostentragung außerkantonaler Spitalbehandlung geschuldet werden, sondern auch teilweise in der Form, daß die unechten Mehrleistungen nur durch bestimmte vom Versicherer vorgegebene Leistungserbringer durchzuführen sind. Damit wirkt das Privatversicherungsverhältnis auf das Sozialversicherungsverhältnis ein, indem bei der Spitalauswahl der Versicherte sich gebunden fühlt, vor allem weil er unechte Mehrleistungen in Anspruch nehmen möchte. Tatsächlich und rechtlich behindert ihn dies bei der Spitalauswahl im Sinne des Sozialversicherungsverhältnisses nicht mehr als andere, denn ihm stehen hinsichtlich des Leistungskatalogs der sozialen Krankenversicherung die gleichen Auswahlmöglichkeiten nach dem KVG zur Verfügung, als wenn er keine Zusatzversicherung hätte. Dennoch wird man aufgrund der Leistungen aus einer Hand davon ausgehen müssen, daß solche Zusatzversicherungen Steuerungselemente aufweisen.

\subsection{Zusatzversicherung}

Herausragender Unterschied bei der Auswahl des Spitals zwischen einem Patienten mit Zusatzversicherung gegenüber einem Patienten ohne Zusatzversicherung ist die anders angelegte Kostenübernahme durch die Zusatzversicherung. Mit anderen Worten: Der Unterschied liegt darin, daß Mehrkosten, die nicht von der obligatorischen Krankenversicherung übernommen werden, eventuell von der Zusatzversicherung getragen werden. Warum die obligatorische Krankenversicherung nach dem KVG Kosten nicht übernimmt, kann, weil sie ja die medizinisch notwendige Behandlung zu tragen hat, nur

159 Eugster, Krankenversicherung, Rz. 1093.

160 Ebenda, Rz. 1091.

161 Siehe I.3.1. 
darin begründet sein, daß der Patient Leistungen außerhalb des KVG in Anspruch nimmt. Solche Leistungen, die durch die Zusatzversicherer abgedeckt werden können, sind in der Praxis vor allem bei zwei Sachverhalten anzutreffen: Zum einen bei der aus medizinischen Gründen nicht notwendigen sogenannten außerkantonalen Hospitalisation 162 und zum anderen bei den sogenannten unechten Mehrleistungen. Beiden Sachverhalten ist gemein, daß das KVG sie unterschiedslos nicht als Spitalleistungen der obligatorischen Krankenversicherung ansieht, demnach sie als Nichtleistungen gleich behandelt. Tatsächlich haben sie aber bei der Auswahl eines Spitals aufgrund der jeweiligen Art der Zusatzversicherung (und damit zuvor bei der Auswahl der Zusatzversicherung) ${ }^{163}$ unterschiedliche Ansätze:

Die aus medizinischen Gründen nicht notwendige außerkantonale Behandlung164 birgt für den Patienten ein finanzielles Risiko ${ }^{165}$, nicht weil er Leistungen außerhalb des Leistungskatalogs des KVG in Anspruch nimmt, sondern weil die Leistungen durch ein Spital erbracht werden, das nach dem KVG diese nicht als Spitalleistungen der obligatorischen Krankenversicherung für diesen Patienten erbringen kann. Mit anderen Worten: Der Patient erweitert nicht den Leistungsinhalt für sich, sondern seine Auswahlmöglichkeiten hinsichtlich der die Leistung erbringenden Spitäler.

Ganz anders verhält es sich bei den unechten Mehrleistungen ${ }^{166}$. Hier nimmt der Patient vom Leistungsinhalt her andere Leistungen in Anspruch, als sie durch das KVG als Pflichtleistungen deklariert werden, also Annehmlichkeiten im Service oder in der Auswahl des Arztes. Der Patient erweitert daher durch die Inanspruchnahme von unechten Mehrleistungen nicht die Auswahlmöglichkeiten hinsichtlich der Erbringer, sondern hinsichtlich des Leistungsinhaltes.

Insgesamt hat der Zusatzversicherungsmarkt auf die oben genannten Bedürfnisse der Versicherten reagiert. Ziel der Policen ist die (teilweise) Übernahme derjenigen Kosten, die weder von der sozialen Krankenversicherung noch vom Kanton übernommen werden. Damit erweitert die Zusatzversicherung die Auswahlmöglichkeiten entweder nach dem Inhalt der Leistung oder nach dem Erbringer der Leistung, wobei oftmals auch beides anzutreffen ist. Jedoch darf nicht verkannt werden, daß verschiedene Policen das „erweiterte“ Angebot dadurch einschränken, daß es nur durch bestimmte Spitäler, mit denen der Zusatzversicherer Verträge eingegangen ist, erbracht werden kann. ${ }^{167}$

$162 \mathrm{Zu}$ den Problematiken und Chancen außerkantonaler Hospitalisation vgl. insgesamt: Gächter (ed.), Ausserkantonale Hospitalisation.

163 Siehe II.2.2.

164 Zur Bedeutung der außerkantonalen Behandlung siehe: Meyer, Schranken und Freiräume, S. 3-4; Jordi, Bedeutung der ausserkantonalen Hospitalisation, S. 87-96.

165 Siehe II.1.1.2.

166 Zum Begriff unechte Mehrleistungen siehe Eugster, Grund- und zusatzversicherte Leistungen im Spitalbereich, S. 16-20.

167 Siehe II.1.1.7. 


\section{Verbraucherorientierte Anreize der Versicherungswahl}

\subsection{Obligatorische Krankenversicherung}

\subsubsection{Wahlfreiheit, Versicherungspflicht und Kontrahierungszwang}

Kernelemente des KVG sind die Versicherungspflicht für die Wohnbevölkerung, die Wahlfreiheit des Versicherten und der Kontrahierungszwang seitens der Versicherer. Während die Versicherungspflicht fast alle Personen, die in der Schweiz leben oder arbeiten, 168 in das System des KVG zwingt und somit nicht freistellt, ob man sich versichert, ermöglichen einerseits die Freiheit der Versicherten, sich den Versicherer nach Art. 4 Abs. I KVG aussuchen zu können, und andererseits die Pflicht seitens der Versicherer, gemäß Art. 4 Abs. II KVG in ihrem örtlichen Tätigkeitsbereich jedermann aufnehmen zu müssen, wie man sich versichert. Damit schafft das KVG den Freiraum, um für bestimmte Versicherungsverhältnisse zu optieren.

Die Kantone haben zu überwachen, ob der Versicherungspflichtige seiner Pflicht nachkommt, und ihn gegebenenfalls zwangsweise zu versichern. ${ }^{169}$ Der Verstoß gegen die Versicherungspflicht führt auch zu Sanktionen in der Weise, daß sowohl die Prämien nachgezahlt werden müssen, als auch ein Prämienzuschlag für die pflichtige nicht versicherte Zeit zu bezahlen ist ${ }^{170}$. Ein solcher Zuschlag liegt zwischen 30 und $50 \%$ der normalen Prämie. ${ }^{171}$

Der Kontrahierungszwang der Versicherungen ist umfassend zu verstehen. Die Versicherungen dürfen nicht nach Risiken selektieren, wie dies im alten KUVG noch möglich war. ${ }^{172}$ Allerdings dürfen regional wirkende Versicherungen nur Versicherte, die in ihrem Wirkungsbereich wohnen, gemäß Art. 4 Abs. II KVG aufnehmen. Schweizweit agierende Versicherungen haben alle Personen aufzunehmen. Das Verbot zu Selektieren 173 bedeutet nur, daß administrative oder andere Schikanen zu unterlassen sind, jedoch nicht, daß sich die Versicherungen nicht um die guten Risiken bemühen dürften.

Wahlfreiheit und Kontrahierungszwang finden ihre Grenzen in den Vorschriften über den Wechsel der Versicherung nach Art. 7 Abs. I und II KVG ${ }^{174}$. Demnach muß der Versicherte mit einer Dreimonatsfrist zum Ende des Kalenderhalbjahres die Versicherung ordentlich kündigen, was ihm in jedem Falle zusteht, und er kann im Falle der Prämienerhöhung unter Einhaltung einer einmonatigen Frist zum Ende eines Monates

168 Die zahlenmäßig geringfügigen Ausnahmen sind in den Art. 3 Abs. II-IV KVG und Art. 2-6 KVV genannt.

169 Art. 6 Abs. I und II KVG.

170 Art. 5 Abs. II KVG.

171 Art. 8 Abs. I KVV.

172 Maurer, Bundessozialversicherungsrecht, S. 252, 265-269 und 259.

173 Zur Kasuistik des EVG vgl. Eugster, Krankenversicherung, Rz. 127.

174 Sowie der Art. 64a KVG, 94 Abs. II, 97 Abs. II und 100 Abs. II KVV. 
außerordentlich kündigen, wobei ihm insgesamt ab Kenntnis der Prämienerhöhung zwei Monate Bedenkzeit einzuräumen sind. Abweichend hiervon sind die Vorschriften über die Wechselfreiheit in Bezug auf besondere Versicherungsverhältnisse. ${ }^{175}$ Wer eine Wahlfranchise vereinbart, kann nur zum Ende des Kalenderjahres ordentlich kündigen; ${ }^{176}$ gleiches gilt für Teilnehmer an Hausarzt- und HMO-Modellen; ${ }^{177}$ wer an einer Bonusversicherung teilnimmt, kann nur zum Ende des fünften Versicherungsjahres ordentlich kündigen. 178

Um den Wechsel zu ermöglichen und Erschwerungen zu verhindern, hat das Gesetz in Art. 7 Abs. V KVG einen eigenen Haftungstatbestand für Versicherungen eingeführt, wonach Schäden aufgrund des Verschuldens der Versicherung dem Versicherten auszugleichen sind.

\subsubsection{Wahlfreiheit und Pflichtmitgliedschaften nach Arbeits- oder Verbandsrecht}

Weiterhin gibt es auch im neuen Recht des KVG arbeits- oder verbandsrechtliche Pflichten zum Beitritt zu einer bestimmten Versicherung. Sie sind als Überbleibsel des alten KVUG weiterhin zulässig. ${ }^{179}$ Dennoch muß die Versicherungen es akzeptieren, wenn der Pflichtige nicht beitritt oder der Versicherte wechseln will. ${ }^{180}$ Dem Versicherten steht es also sozialversicherungsrechtlich vollkommen frei, ob er die arbeitsoder verbandsrechtlichen Pflichten erfüllen möchte.

\subsubsection{Leistungen und Prämien}

Anreize zur Wahl eines Versicherers können im Leistungsangebot und/oder in der Höhe der Beiträge liegen. Bei ersterem sind im schweizerischen System der obligatorischen Krankenversicherung keine Anreize vorhanden, weil alle Leistungen, die erbracht werden, sich am Leistungskatalog 181 zu orientieren haben. Die Versicherungen dürfen demnach weder andere, noch Mehrleistungen noch Minderleistungen anbieten. Sie müssen dem Versicherten dasjenige gewähren, was als Pflichtleistungen nach dem Leistungskatalog Gegenstand der obligatorischen Krankenversicherung ist.

Demnach liegt der eigentliche Anreiz für die Versicherten in der Gestaltung der Prämie ${ }^{182}$ durch die Versicherung. Die Prämie ist eine Individualprämie, unabhängig von Einkommen oder Vermögen. Sie muß nach dem Prinzip der Einheitsprämie gestaltet sein, was nichts anderes heißt, als daß die Prämie für alle Versicherten gleich hoch sein muß, unabhängig von ihrem Geschlecht, Alter, Morbiditätsrisiko oder sonstigen in

175 Dazu näher unter II.2.1.

176 Art. 94 Abs. I-II KVV

177 Art. 100 Abs. III-IV, 94 Abs. II-III KVV.

178 Art. 97 Abs. II KVV.

179 Maurer, Krankenversicherungsrecht, S. 37.

180 Eugster, Krankenversicherung, Rz. 125.

181 Siehe I.3.1.

182 Zur Prämiengestaltung im Einzelnen siehe II.3.1. 
der Eigenschaft der Person liegenden Gründen. Einheitsprämie heißt aber auch, daß die Höhe der Prämie für alle Personen in einem geographisch abgrenzbaren Raum gleich sein muß. Demnach darf der Versicherer auch innerhalb eines Kantons differenzieren aufgrund von Art. 61 Abs. I-II KVG, also beispielsweise für die Bevölkerung der Kantonshauptstadt andere Prämien ansetzten als für diejenige einer Landgemeinde. Das Prinzip der Einheitsprämie wird nur hinsichtlich des Alters durchbrochen, weil nach Art. 61 Abs. III KVG für junge Erwachsene und Minderjährige niedrigere Prämien anzusetzen sind.

Trotz des Prinzips der Einheitsprämie und des manifestierten gleichen Leistungsangebotes aller Krankenversicherungen nach dem KVG gibt es beträchtliche Unterschiede in der Höhe der Prämie. ${ }^{183}$ Erst hierdurch wird faktisch ein Anreiz für die Versicherten gesetzt, Prämien zu vergleichen und für die Wahl des Versicherers heranzuziehen.

\subsubsection{Prämien bei besonderen Versicherungsformen}

Außerhalb der normalen Prämie gibt es im KVG auch Prämienermäßigungen. Sie finden überall dort Eingang, wo der Versicherte sich entweder höher an den jährlichen Behandlungskosten beteiligt oder wo der Versicherte seine Wahlfreiheiten bezüglich des Leistungserbringers einschränkt. Bei alle diesen Prämienermäßigungen gilt aber auch das Prinzip der Einheitsprämie, hier dergestalt, daß die höhere Selbstbeteiligung oder die Einschränkungen in der Wahlfreiheit wiederum nicht zu Prämienreduktionen aufgrund von Alter, Geschlecht oder Morbiditätsrisiko führen dürfen. Weiterhin gilt, daß der Versicherer keine anderen Leistungen als diejenigen des Leistungskatalogs anbieten darf.

Das System der Wahlfranchise nach Art. 62 Abs. II lit.a KVG beinhaltet die höhere Selbstbeteiligung an den jährlichen Behandlungskosten als im gesetzlichen Normalfall, wo nach Art. $103 \mathrm{KVV}$ bereits jeder Versicherte $300 \mathrm{CHF}$ selbst zu tragen hat. Als Höchstgrenze der Wahlfranchise ist zur Zeit der Betrag von jährlichen 2500 CHF festgelegt nach Art. 93 Abs. I KVV.

Die Bonusversicherung nach Art. 62 Abs. II lit.b KVG gibt dem Versicherten einen Prämienbonus, wenn er während eines Kalenderjahres weder stationäre noch ambulante Leistungen in Anspruch genommen hat, wobei Leistungen der Mutterschaft und Leistungen der medizinischen Prävention nicht dazu gehören. ${ }^{184}$

Versicherungsmodelle mit einer Ärzteliste (Preferred-Provider-Organization) schränken die Wahl der Leistungserbringer danach ein, daß der Versicherte nur Erbringer dieser Liste in Anspruch nehmen darf. ${ }^{185}$ In Notfallsituationen dürfen aber, wie auch bei HMO- oder Hausarztmodellen, andere Leistungserbringer in Anspruch genommen werden.

183 Eugster, Krankenversicherung, Rz. 999.

184 Art. 96 Abs. I KVV.

185 Eugster, Krankenversicherung, Rz. 1093. 
Bei den HMO-Modellen schränkt der Versicherte seine Wahlfreiheit dadurch ein, daß er sich verpflichtet, sich nur von den Erbringern des HMO untersuchen oder behandeln und gegebenenfalls von diesen an Dritte überweisen zu lassen. Dadurch soll der gesamte Behandlungsprozeß aus einer Hand geschehen. Neben dem finanziellen Anreiz der Prämienreduktion ist dieses Modell das einzige, das auch Anreize in der Behandlung schafft. Zwar werden auch hier nur Leistungen nach dem Leistungskatalog des KVG gewährt, doch bieten sich die HMO insbesondere für Personengruppen an, die eine hohe Interaktionsdichte zwischen den Leistungserbringern benötigen, wie dies etwa bei chronischen Krankheiten der Fall sein kann. Die HMO sind fast ausschließlich Gründungen der Krankenversicherungen und verwalten ein Globalbudget für jeden Versicherten. ${ }^{186}$ Sie sind aber bis heute nicht schweizweit verbreitet. Der Versicherte kann sie nur in den Agglomerationen der Deutschschweiz sowie in einigen städtischen Zentren der Romandie finden. 187

Schließlich seien noch die Hausarztmodelle genannt, bei denen sich der Versicherte verpflichtet, immer erst einen bestimmten Allgemeinpraktiker (gatekeeper) aufzusuchen, der ihn wiederum an Spezialisten oder an Spitäler überweist. Auch hierbei gibt es eine Budgetverantwortung seitens des gatekeeper. 188

Insgesamt haben die Anreize der Prämienreduktionen bei den vorgenannten besondern Versicherungsformen dazu geführt, daß in der Schweiz im Jahre 2006 nur noch $44 \%$ aller Versicherten über eine „,normale“ Versicherung verfügten, 189 also nur noch $44 \%$ der Versicherten weder ihre Selbstbeteiligung erhöht hatten noch Leistungserbringungseinschränkungen hinnahmen. Neben den Prämienreduktionen gibt es bei den Hausarzt- und HMO-Modellen aber noch einen weiteren finanziellen Anreiz, der nicht unterschätzt werden darf: Im Gegensatz zum sonstigen Kostenerstattungsprinzip im KVG verpflichten sich die Versicherer in den vorgenannten Modellen zur Naturalleistung. ${ }^{190}$ Der Versicherte muß also nicht in Vorleistung treten, sondern kann die Leistung in Anspruch nehmen, ohne Kostenschuldner gegenüber dem Leistungserbringer, wie etwa dem Spital, zu sein.

\subsubsection{Kostenerstattungsprinzip und Naturalleistungsprinzip}

Das schweizerische System der Krankenversicherung ist, wie bereits häufiger erwähnt, geprägt vom Kostenerstattungsprinzip. Dieses sogenannte System des tiers garant beinhaltet nach Art. 42 Abs. I KVG, daß der Patient Kostenschuldner des Leistungserbringers ist, was insbesondere bei Spitalleistungen eine erhebliche finanzielle Belastung darstellt, die sich nicht nur momentan äußert, sondern hinsichtlich der Aus-

186 Ebenda, Rz. 1090.

187 Baumberger, Managed Care, S. 174.

188 Eugster, Krankenversicherung, Rz. 1090.

189 Bundesamt für Sozialversicherungen, Schweizerische Sozialversicherungsstatistik 2008, S. 151.

190 Eugster, Krankenversicherung, Rz. 1086. 
wahl des Spitals auch zu einem Kostenrisiko werden kann. ${ }^{191}$ Versicherungen können aber auch das System des tiers payant anbieten, wo der Versicherer an die Stelle des Kostenschuldners tritt nach Art. 42 Abs. II S. 2 KVG, allerdings nur für denjenigen Anteil, den er sonst auch beim tiers garant nachträglich zu leisten hätte, womit die Leistungspflicht des Kantons an den Erbringer unberührt bleibt. ${ }^{192}$ Immerhin könnte das System der Naturalleistung für Versicherte einen Anreiz setzen, mit solchen Versicherungen eine Mitgliedschaft zu vereinbaren, die ihn aufgrund des tiers payant finanziell entlasten. Ob dies tatsächlich Anreize gibt oder ob es, abgesehen von den HMO- und Hausarztmodellen, überhaupt Angebote seitens der Versicherungen gibt, ist in den sonst bekannten Statistiken zum Krankenversicherungswesen nicht verzeichnet.

\subsection{Zusatzversicherung}

Der Zugang zu den Zusatzversicherern richtet sich aufgrund des KVG nach dem VVG. Damit gibt es für die privaten Anbieter von Zusatzversicherungen keinen Aufnahmezwang und damit keinen Kontrahierungszwang. Aufgrund von Art. 12 KVG können die sozialen Krankenkassen ebenfalls solche Zusatzversicherungen anbieten. Jedoch ist auch hier davon auszugehen, daß die Zusatzversicherung der sozialen Krankenkasse, gleich ob sie sie selbst oder durch ausgegliederte Organisationen durchführt, nicht zu einem Kontrahierungszwang führt. 193 Ein verfassungsrechtlicher Anspruch auf Aufnahme besteht, anders als beim Thema der Aufnahmepflicht durch öffentliche Spitäler, wohl nicht.

Der Patient, der sich eine Zusatzversicherung aussuchen möchte, wird aber nicht nur damit konfrontiert, daß ihn generell niemand aufnehmen muß. Vielmehr richten sich die Prämien auch nach der individuellen Risikoeinschätzung, wonach ältere und damit für Krankheiten anfälligere Personen mit erheblich höheren Prämien zu rechnen haben. Risikoselektion ist daher gang und gäbe bei den Zusatzversicherern. Daß selbst die sozialen Krankenkassen dies so betreiben, obwohl ihnen nach Art. 12 Abs. 2 KVG auch im Zusatzversicherungsbereich jeder Erwerbszweck untersagt ist, wird zwar gesellschaftlich als Problem angesehen, jedoch mit versicherungsmathematischen Grundsätzen gerechtfertigt. ${ }^{194}$ Solchen Einschätzungen wird man zu Gute halten müssen, daß das Konzept des obligatorischen Krankenversicherungssystems Risikoselektion nicht zuläßt und gleichzeitig das medizinisch Notwendige auf hohem Niveau für alle bereitstellt, somit Zusatzversicherungen Annehmlichkeiten anbieten, deren Luxus Geld kostet. Hier wird man aber grundsätzlicher zu fragen haben, warum die sozialen Kranken-

191 Siehe I.3.1., I.3.2. und II.1.1.2.

192 Nach dem zum 1. Januar 2009 neu eingeführten Art. 49a Abs. 3 KVG leistet der Kanton direkt an das Spital, es sei denn, Versicherer und Kanton haben vereinbart, daß der Kanton seinen Anteil an den Versicherer und dieser beide Anteile an das Spital überweist.

193 Streit, Zusatzversicherungen nach Versicherungsvertragsgesetz, S. 224.

194 Ebenda, S. 223-224. 
kassen sich überhaupt auf diesem Markt verhalten sollen, ist ihnen doch jeder Erwerbszweck untersagt und hat der Staat, mithin die mittelbare Staatsverwaltung in Form der sozialen Krankenkassen unternehmerische Aktivitäten soweit wie möglich zu unterlassen. ${ }^{195}$

Was Gegenstand der Zusatzversicherung ist, könnte somit frei verhandelbar sein. Tatsächlich wird man wohl eher davon ausgehen können, daß der Zusatzversicherer Leistungen anbietet, die der Interessierte abzuwägen hat. Einen vorgegebenen Mindestkatalog gibt es nicht, so daß der Versicherer auf Basis seiner Kalkulationen das Leistungspaket bestimmt. Dennoch gibt es selbst hier Einschränkungen, kann der Interessierte nicht alles auf dem Markt finden, wogegen er sich gerne absichern möchte. Dabei ist an erster Stelle das Verbot zu nennen, wonach die gesetzlich vorgesehenen Kostenbeteiligungen der Patienten (Franchise, Selbstbehalt etc.) gemäß Art. 64 Abs. VIII KVG in keinem Falle von einer Schweizer Versicherung versichert werden dürfen. Darüber hinaus besteht das Verbot der Doppelversicherung, will heißen: Leistungen nach dem KVG dürfen nicht in einer anderen Versicherungen versichert werden. ${ }^{196}$ Demnach ist die Zusatzversicherung immer Komplementärversicherung. Dabei ist allerdings bedenklich, daß das Leistungsangebot der Zusatzversicherer nicht immer nur komplementär ist, wie dies offensichtlich bei den Annehmlichkeiten von Service oder Arztwahl gegeben ist, sondern die Zusatzversicherer auch die medizinisch nicht notwendige außerkantonale Behandlung gegen die hieraus für den Patienten resultierenden, weil nicht vom Kanton oder seiner Krankenkasse abgedeckten Kosten versichert, obwohl die Leistung selbst schon durch die obligatorische Krankenversicherung und/oder den Kanton abgedeckt wäre, wenn sich der Patient in ein zu Leistungen an ihn berechtigtes Spital begeben würde. 197

\section{Wettbewerbsbeziehungen zwischen Kostenträgern und Krankenhäusern}

\subsection{Obligatorische Krankenversicherung}

Das Verhältnis zwischen den Krankenversicherungen und den Spitälern ist im KVG vornehmlich durch das Tarifrecht geprägt. Dabei gilt der Grundsatz, daß kein Leistungserbringer einseitig Tarife und Preise bestimmen kann. ${ }^{198}$ Demnach haben sich die Tarifparteien auf einen Tarif zu einigen. Das Ziel eines Tarifes muß gemäß Art. 43 Abs. VI KVG immer die qualitativ hochstehende Versorgung zu möglichst günstigen Kosten sein. Beide Vertragsparteien müssen demnach die Qualität der Versorgung im Auge

195 Siehe dazu: II.5.2.

196 Eugster, Krankenversicherung, Rz. 198, mit Verweisen auf die Rechtsprechung des Bundesgerichts hierzu in Fn. 294.

197 Siehe hierzu: II.1.2.

198 Eugster, Krankenversicherung, Rz. 838. 
haben, die Versicherungen weiterhin die Kostengünstigkeit, die Spitäler vor allem die Kostendeckung.

\subsubsection{Tarifvertrag, Behördentarif, Ersatztarif}

Die Tarifparteien haben über die Spitalleistungen einen Tarif auszuhandeln nach Art. 46 und 49 KVG. Nicht in ihren Zuständigkeitsbereich fällt nach Art. 52 Abs. I KVG die Tarifierung für die Vergütung von Analysen und Arzneimitteln sowie für Mittel und Gegenstände. Diese Tarife sind Behördentarife und werden vom EDI festgesetzt. Kommt ein Tarif, aus welchen Gründen auch immer, nicht zustande, hat der Kanton als Genehmigungsbehörde gemäß Art. 47 Abs. I KVG einen Ersatztarif zu erlassen.

\subsubsection{Tarifvertragsparteien und Wettbewerb}

Die Tarifparteien können einzeln oder kollektiv Tarifverträge aushandeln nach Art. 46 Abs. I KVG. Der Praxis entspricht es, daß die Verbände auf kantonaler Ebene, insbesondere $H+$ für die Spitäler und santesuisse für die Versicherungen, Tarifverträge abschließen. Wettbewerbswidrig, schon nach dem KVG, sind vertikale Tarifverträge in dem Sinne, daß Einzelne einem Verband gegenüberstehen. Art. 46 Abs. III lit.d KVG ist damit schon auf der Ebene des KVG eine Bestimmung zum Verbot marktbeherrschender Stellung von Kartellen. ${ }^{199}$ Etwas anderes gilt für die Kollektivverträge. Sie sind nach Art. 46 Abs. I KVG statthaft und stellen somit einen Vorbehalt dar, der die Anwendung des KG aufgrund bundesgesetzlicher Regelung ausschließt. ${ }^{200}$

\subsubsection{Tarifvertragsinhalt und Preisüberwachung}

Die Mehrzahl von neuen Tarifverträgen beinhaltet Preiserhöhungen, die von den Kantonen zu genehmigen sind. Damit kommt Art. 14 PüG zur Anwendung. Demnach ist bei behördlich zu genehmigenden oder festzusetzenden Preiserhöhungen immer der Preisüberwacher ${ }^{201}$ anzuhören. Er kann die Senkung des Preises beantragen oder den Verzicht auf die Erhöhung. Will der Kanton hiervon abweichen, hat er dies ausführlich zu begründen. Eine Nichtanhörung des Preisüberwachers führt in jedem Falle zur Nichtigkeit des Tarifvertrages. Der Preisüberwacher überprüft vor allen Dingen die Wirtschaftlichkeit der Tarife und hierbei insbesondere, ob ein Mißbrauch in der Preisbildung vorliegt. In zahlreichen Fällen hat das Votum des Preisüberwachers dazu geführt, daß die Tarifverträge in anderer Form in Kraft getreten sind, als sie zuvor noch von den Tarifparteien ausgehandelt worden sind.

199 Schaller/Tagmann, Kartellrecht und öffentliches Recht, S. 709.

200 ReKo RPW 2003, 514.

201 Vgl. I.4.2. 


\subsubsection{Tarife und Pauschalen}

Gegenstand der Vergütung sind feste Tarife oder Pauschalen. Dabei läßt das Gesetz zunächst einen weiten Spielraum, was vereinbart werden kann: Der Zeittarif nach Art. 43 Abs. II lit.a KVG entschädigt nach dem Zeitaufwand. Mit dem Einzelleistungstarif nach Art. 43 Abs. II lit.b KVG werden die Einzelleistungen in Rechnung gestellt. Hingegen werden bei den Pauschalen gemäß Art. 43 Abs. II lit.c KVG die erbrachten Leistungen pauschal nach bestimmten Mustern abgegolten. Letztere Kategorie läßt sich wiederum in Kopfpauschale, Tagespauschale und Fallpauschale unterscheiden. ${ }^{202}$ Nach Art. 49 Abs. I S. 1 KVG wird die stationäre Behandlung durch Pauschalen abgegolten. Andere Tarifarten waren gemäß Art. 49 Abs. II aF KVG grundsätzlich, aber nur in Einzelfällen möglich. Von dieser Öffnung ist man nun abgerückt. In Art. 49 Abs. I S. 4 heißt es daher nur noch: „Die Vertragsparteien können vereinbaren, dass besondere diagnostische oder therapeutische Leistungen nicht in der Pauschale enthalten sind, sondern getrennt in Rechnung gestellt werden. " Damit bleibt grundsätzlich nur noch für die genannten Leistungen die Möglichkeit, anderes zu bestimmen. ${ }^{203}$ Ansonsten hat die Teilrevision des KVG, grundsätzlich in Kraft getreten am 1. Januar 2009, dazu geführt, daß nicht nur Pauschalen prinzipiell zu vereinbaren sind, sondern daß gemäß Art. 49 Abs. I S. 2 in der Regel „Fallpauschalen festzulegen“ sind. Diese haben nach Art. 49 Abs. I S. 3 leistungsbezogen zu sein und müssen auf ,gesamtschweizerisch einheitlichen Strukturen" beruhen.

Bei den Fallpauschalen ist hervorzuheben, daß sie bereits seit 2002 verstärkt in den Spitälern als sogenannte DRG-Pauschalen angewendet werden, besser bekannt unter dem Stichwort SwissDRG. ${ }^{204}$ Dabei werden Patientenklassifikationssysteme benutzt, um die einzelnen Fallpauschalen zu ermitteln. ${ }^{205}$ Jeder Patient wurde daher einer der 600 diagnosebezogenen Fallgruppen im Spital zugewiesen. In diesem Vergütungssystem bestimmten die Tarifpartner für jedes Spital oder für Spitalgruppen oder für alle Spitäler Basispreise für die einzelnen Klassifikationen. ${ }^{206}$ In der Schweiz wird seit 2007 eine modifizierte Version des GermanDRG verwendet, die 912 Fallgruppen ausweist. Diese Art der diagnosebezogenen Fallgruppen ${ }^{207}$ hat mit der Teilrevision des KVG nun auch im Gesetz selbst seinen Niederschlag gefunden. ${ }^{208}$ Insbesondere ist eine Organisation durch die Tarifpartner und die Kantone zu schaffen, welche für die Erarbeitung und Weiterentwicklung sowie die Anpassung und Pflege der Strukturen zur

202 Eugster, Krankenversicherung, Rz. 840-843.

$203 \mathrm{Zu}$ beachten gilt dabei allerdings, daß die Kantone als finanzielles Steuerungsinstrument gemäß Art. 50 Abs. I KVG weiterhin einen Gesamtbetrag als Globalbudget für die Finanzierung der Spitäler festsetzen können.

204 Vgl. hierzu insgesamt Indra, SwissDRG.

205 Ausführlich dazu aus ökonomischer Sicht: Malk/Kampmann/Indra, DRG-Handbuch Schweiz.

206 Eugster, Krankenversicherung, Rz. 843.

207 Zur Kritik an solchen Pauschalen vgl. Hanhart, Diagnosebezogene Fallpauschalen.

208 Vgl. hierzu insgesamt Art. 49 nF KVG. 
Ermittlung schweizweit einheitlicher Fallpauschalen zu sorgen hat. Schließlich muß noch hervorgehoben werden, daß das genannte System der diagnose- und leistungsbezogenen Fallpauschalen aufgrund gesamtschweizerischer Strukturen erst bis Ende 2011 umzusetzen ist. ${ }^{209}$

\subsection{Zusatzversicherung}

Das Zusatzversicherungswesen ist ebenfalls von Vereinbarungen zwischen den Spitälern und den Versicherern geprägt. Auch dort geht es um Tarife oder Pauschalen. Viel stärker als bei der obligatorischen Krankenversicherung kommt hier allerdings das Kartellgesetz (KG) zur Anwendung. ${ }^{210}$ Insbesondere bei Kollektivverträgen ist immer die Frage nach einer marktbeherrschenden Stellung nach Art. $5 \mathrm{KG}$ zu stellen. Auch die nach dem Privatrecht an sich zulässigen Vereinbarungen zwischen Einzelnen und Verbänden rufen immer Besorgnis hervor, ob hier nicht die nach Art. $5 \mathrm{KG}$ untersagten horizontalen Vereinbarungen mit vertikaler Auswirkung zum Tragen kommen. ${ }^{211}$

Die Anwendbarkeit des KG auf solche Verträge kann auch kaum unter Vorbehalt gestellt worden sein. Denn nach Art. 3 KG könnte dies nur aufgrund bundesstaatlicher oder kantonaler Gesetze geschehen. Bundesstaatliche Vorbehalte sind aber nicht gegeben, weil das KVG im Zusatzversicherungswesen auf das Vertragsversicherungsgesetz (VVG) verweist, das gerade den Wettbewerb zwischen Versicherern und Leistungserbringern nicht ausschließt. ${ }^{212}$ Aber auch kantonale Vorbehalte sind kaum möglich, zumal sich sowohl das KVG als auch das VVG der Kompetenz der Kantone entzieht und kantonale Gesundheitsgesetze auch die Zusatzversicherungen nicht zum Gegenstand haben. ${ }^{213}$

\section{Wettbewerb zwischen Krankenhäusern}

Mit fast 900.000 stationär behandelten Personen im Jahre $2005^{214}$ und schon über 920.000 im Jahre 2007215 handelt es sich beim Spitalwesen in der Schweiz um einen großen und attraktiven Markt. Um das Angebot wahrnehmen zu können, hängen nicht nur die Patienten sondern auch die Spitäler von Versicherungen ab, welche einen Teil der Kosten für die Behandlung übernehmen. Diese leisten aber nur aufgrund des KVG

209 Vgl. am Textende des KVG den Abs. 1 der Übergangsbestimmungen zur Änderung vom 21. Dezember 2007.

210 Vgl. I.4.2.

211 Schaller/Tagmann, Kartellrecht und öffentliches Recht, S. 709.

212 ReKo RPW 2006, 515.

213 ReKo RPW 2006, 524-525.

214 Bundesamt für Statistik, Spitalaufenthalte 2005, S. 8

215 Bundesamt für Statistik, Statistik der Krankenhäuser 2007, Tabelle C1. 
oder aufgrund der privatrechtlichen Versicherungsverträge. Da die gesamte Wohnbevölkerung nach dem KVG versichert ist, haben sich die Spitäler in ihrem Wettbewerb untereinander vor allem an diesem System auszurichten. Dennoch ist das Zusatzversicherungswesen so attraktiv, daß selbst die öffentlichen Spitäler Halbprivat- und Privatabteilungen betreiben. Im Wettbewerb der Spitäler geht es daher um beide Finanzierungs- und Regelungsformen, zumal die Zusatzversicherung zumeist nur eine Ergänzung ist. Daher sollen im Folgenden, abweichend von der bisherigen Systematik, beide Versicherungsformen zusammenbehandelt werden, soweit es sinnvoll erscheint.

\subsection{Struktur und Status}

Die fundamentale Unterscheidung im Spitalwesen wird danach getroffen, ob es sich um ein öffentliches Spital bzw. öffentlich subventioniertes Spital oder um ein privates Spital handelt. 216 Denn nach dieser Unterscheidung richten sich im KVG die Möglichkeiten und Grenzen des Wettbewerbes untereinander aus. Von geringerer Bedeutung ist demnach die Verfaßtheit der Spitäler, wobei die öffentlich-subventionierten und die privaten jede privatrechtliche Form wählen dürfen. Die Verfaßtheit selbst mag betriebswirtschaftlich von großer Bedeutung sein; im Wettbewerb untereinander ist sie eine juristisch zu vernachlässigende Größe. Dem steht auch nicht entgegen, daß die öffentliche Hand im Trend dazu übergeht, die öffentlichen Spitäler nach und nach zu privatisieren. $^{217}$

Neben der vorgenannten Einordnung ist es von besonderer Bedeutung, ob die Spitäler auf einer Spitalliste aufgenommen werden. Denn ohne eine solche Aufnahme können die Spitäler keine Leistungen nach dem KVG erbringen und können somit nicht in den Wettbewerb um die KVG-Versicherten treten. Dies gilt vor allem für die privaten Spitäler, weil die öffentlichen Spitäler immer Eingang in die Spitalliste finden, die öffentlich-subventionierten fast immer aufgenommen werden. ${ }^{218}$

Dieser durchgängigen faktischen wie rechtlichen Bevorzugung der öffentlichen Spitäler, ohne hier auf die Einzelheiten bereits einzugehen, kommt gleich, daß die Wettbewerbskommission eine marktbeherrschende Stellung der Kantonsspitäler, die es ja in jedem Kanton mindestens einmal gibt, abgelehnt hat, nicht zuletzt weil ein Kantonsspital der grundsätzlichen Gesundheitsversorgung dient. ${ }^{219}$ Damit werden wohl private Konkurrenten zukünftige Anträge an die Wettbewerbskommission, mit dem Ziel den Markt offener zu gestalten, nicht stellen, wenn es um die öffentlichen Kantonsspitäler geht.

Trotz der im schweizerischen System angelegten Bevorzugung der öffentlichen Spitäler zeigt es sich, daß es eher zu Konzentrationen bei den öffentlichen bzw. öffentlich

217 Schwarz, Privatisierung von Spitälern, S. 76 ff.

218 Siehe hierzu II.4.2.

219 ReKo RPW 1998, 592 
subventionierten Spitäler als bei den privaten Spitälern kommt, nahmen erstere doch deutlich mehr in ihrer Anzahl ab als letztere. ${ }^{220}$ Dies hat seinen Grund auch darin, daß die privaten Spitäler vor allem bei Spezialkliniken dominant sind: von 45 Rehabilitationskliniken waren 27 private, von 40 Spezialkliniken der Chirurgie, Gynäkologie/Neantologie oder Pädiatrie waren 33, von 35 Spezialkliniken anderer Fachrichtungen 17 private Spitäler. Die Spezialisierung schafft den privaten Spitälern einen gewissen Vorsprung, der letztendlich auch dazu führt, daß sie aufgrund der kantonalen Spitalplanung, die eine ausreichend Versorgung gewährleisten soll, auch auf die Spitallisten aufgenommen werden. Hingegen ist das Vorkommen von privaten Spitälern der Zentrumsversorgung mit breitem medizinischen Angebot verschwindend, bei den Spitälern der Grundversorgung bei ca. 25\%. ${ }^{221}$ Grundsätzlich läßt sich damit festhalten, daß die privaten von vornherein konkurrenzfähiger bei Spezialkliniken sind als bei den Grundund Zentrumsversorgern.

\subsection{Spitalplanung und Spitallisten}

Nach Art. 39 Abs. I lit.d KVG soll die kantonale Spitalplanung eine optimale Ressourcennutzung, einen Abbau von Überkapazitäten und damit eine Dämpfung der Kosten bewirken. Die Instrumente zur Spitalplanung sind die Formulierung von Leistungsaufträgen und die Zuweisung von Bettenzahlen. ${ }^{222}$ Die Bedarfsermittlung erfordert die Ermittlung des Angebotes an stationärer Versorgung im Kanton und wird dem Bedarf der obligatorisch versicherten Personen im Kanton gegenübergestellt. ${ }^{223}$ Darüber hinaus müssen auch der Bedarf für die Patienten der Halbprivat- und Privatabteilungen ermittelt werden. ${ }^{224}$ Der Abbau von Überkapazitäten geht nur nach der Bedarfsplanung und nicht nach dem Wettbewerb. ${ }^{225}$

Insgesamt erhalten diejenigen Spitäler den Vorzug, welche die Leistungen nach dem Leistungsauftrag bei gleicher Qualität kostengünstiger erbringen, wobei die Versorgungsqualität höher eingestuft werden soll als die Kosteneinsparungen. ${ }^{226}$ Mit letzterem Argument verbunden ist die Kernaussage des Art. 39 Abs. I lit.d KVG, welcher vorschreibt, daß private Spitäler angemessen zu berücksichtigen sind. Dies heißt nicht, daß sie berücksichtigt werden müssen. Die Kantone dürfen bei der Spitalplanung unter den privaten Spitälern nach Ermessen eine Auswahl treffen. 227

220 Bundesamt für Statistik, Spitalaufenthalte 2005, S. 5.

221 Ebenda, S. 7.

222 Eugster, Krankenversicherung, Rz. 747.

223 Eugster, Krankenversicherung, Rz. 750.

224 EVG RKUV 1998 KV 54.

225 EVG RKUV 2001 KV 183.

226 Eugster, Krankenversicherung, Rz. 755-756.

227 Eugster, Krankenversicherung, Rz. 759. 
Grundsätzlich sind die Leistungsaufträge so zu formulieren, daß sie grundsätzlich die Gesundheitsversorgung der Kantonsbevölkerung gewähren, was nichts anderes heißt als das nach Diagnosekriterien zu verfahren ist, so daß auch spezielle medizinische Disziplinen zum Tragen kommen müssen. ${ }^{228}$ Dabei behelfen sich kleinerer Kantone vor allem damit, daß sie außerkantonalen Spezialkliniken einen Leistungsauftrag geben. Konsequenz der gesamten Spitalplanung ist die Erstellung der Spitallisten. Nur wer dort aufgeführt ist, kann gemäß Art. 39 Abs. I lit.e KVG Leistungen nach dem KVG erbringen.

Die Teilrevision des KVG zum 1. Januar 2009 bringt bei der Spitalplanung erhebliche Neuerungen; wenngleich die meisten von ihnen aufgrund der Übergangsbestimmungen erst Ende 2014 verwirklicht sein müssen. ${ }^{229}$ Hiernach haben die Kantone ihre Planungen zu koordinieren (Art. 39 Abs. 2 KVG) und hinsichtlich der hochspezialisierten Medizin eine gesamtschweizerische Planung zu beschließen (Art. 39 Abs. 2bis S. 1 KVG). Kommen sie letzterem nicht nach, legt der Bundesrat fest, welche Spitäler für welche Leistungen auf den kantonalen Spitallisten aufzuführen sind (Art. 39 Abs. 2bis S. 2 KVG). Zur Planung der Kantone erläßt der Bundesrat einheitliche Planungskriterien auf der Grundlage von Qualität und Wirtschaftlichkeit (Art. 39 Abs. 2ter S. 1 KVG). Folgen die Kantone somit den neuen Kriterien in Zukunft und gleichen ihre Spitallisten an, wobei sie weiterhin die privaten Spitäler nur angemessen berücksichtigen müssen (Art. 39 Abs. 1 lit.d), so besteht die Gefahr, daß die Kantone schon ob des nun höheren Finanzierungsanteils ihrerseits und des nun auch an die privaten Spitäler zu leistenden Kantonsbeitrages versuchen könnten, die privaten Spitäler auf ihren Spitallisten $\mathrm{zu}$ verdrängen. Um dies zunächst $\mathrm{zu}$ verhindern, wurde eine Übergangsbestimmung 230 eingeführt, wonach die Kantone wenigstens während des Zeitraums, in welchem die Spitallisten anzupassen sind, verpflichtet werden, ihren Kostenanteil für alle auf den Spitallisten aufgeführten Spitälern weiterhin zu übernehmen. ${ }^{231}$

\subsection{Subventionen}

Die Kantone können einzelnen Spitälern, die privat verfaßt sind, Subventionen oder sonstige Vergünstigungen gewähren. Handelt es sich um eine Subvention, so wird aus dem privaten Spital ein öffentlich-subventioniertes. Die Grundlage für Subventionen oder für andere Vergünstigungen beruhen auf den kantonalen Gesetzen, zumeist auf den Gesundheitsgesetzen. ${ }^{232}$ Die Zuwendungen erfolgen aber nicht ohne Gegenleistung. Insbesondere verpflichtet die Subvention zu bestimmten Vorkehrungen in der Ausstat-

228 EVG RUKV $2001 \mathrm{KV} 183$.

229 Vgl. am Textende des KVG die Abs. 3 und 4 der Übergangsbestimmungen zur Änderung vom 21. Dezember 2007.

230 Vgl. am Textende des KVG den Abs. 4 S. 2 der Übergangsbestimmungen zur Änderung vom 21. Dezember 2007.

231 Rich, Umsetzung der Spitalfinanzierung, Rz. 11.

232 So etwa $\S 71$ GesG ZH. 
tung des Spitals hinsichtlich der Gesundheitsversorgung. So etwa zur Einrichtung eines Notfalldienstes oder zur Vorhaltung bestimmter Leistungsangebote. ${ }^{233}$ Demnach ist das finanzielle Mehr nicht immer attraktiv, können private Spitäler ohne Zuwendungen freier ihr Angebot gestalten.

Der Vorteil liegt aber nicht nur in der finanziellen Zuwendung, sondern in dem Faktum begründet, daß häufig die öffentlich-subventionierten Spitäler auch auf die Spitalliste aufgenommen werden, wobei hier allerdings kein Automatismus herrscht. ${ }^{234}$ Ein Anspruch auf Subvention besteht je nach Ausgestaltung der kantonalen Gesetze. Dabei wird man wiederum den Grundsatz aufstellen können, daß die Kantone zunächst ihre finanziellen Ressourcen bei den öffentlichen Spitälern einsetzen. Daß aber eine Subvention als solche für das Bestehen auf dem Gesundheitsmarkt noch nicht entscheidend sein muß, zeigt die große Anzahl von privaten Spitälern auf allen kantonalen Spitallisten. Demnach sind es insgesamt immerhin 132 private Spitäler gegenüber 213 öffentlichen bzw. öffentlich subventionierten Spitälern ${ }^{235}$. Demnach ist jedenfalls für diese Spitäler ein Auskommen ohne Subvention möglich, trotz aller Hemmnisse, die eine Nichteinordnung als öffentlich-subventioniertes Spital zur Folge haben kann. ${ }^{236}$

\subsection{Preiswettbewerb?}

Die Tarifgestaltung, wie sie die Normen des KVG vorgibt ${ }^{237}$, scheint es zu ermöglichen, daß die Abgeltung der Spitalleistung je nach Verhandlungsergebnis mit einem Versicherer unterschiedlich hoch sein könnte, so daß die Leistungen bei dem einen oder anderen Spital von vornherein zu mehr Einnahmen oder etwa günstigere Tarife zu mehr Patienten und damit zu kostendeckender Auslastung führen könnten. Dem steht aber schon die Erfahrung aus der Praxis entgegen, wonach die meisten Tarifverträge Kollektivverträge sind, zumeist durch die kantonalen Verbände des Versicherungsverbandes santesuisse einerseits und andererseits des Spitalverbandes $H+$. Demnach agieren die meisten Spitäler hinsichtlich des KVG aufgrund des gleichen Tarifes. Anderes könnte nur dort gelten, wo die Tarifverträge Freiheiten in den Pauschalen geben, so daß etwa das eine Spital seinen Vorteil daraus zieht, vorwiegend Fallpauschalen abzurechnen, ein anderes dadurch, daß es Zeitpauschalen in Anspruch nimmt. Die Einführung der Fallpaschaulen aufgrund gesamtschweizerischer Strukturen 238 beendet voraussichtlich diese Art von Preiswettbewerb, soweit er überhaupt jemals weitgehend bestand, endgültig.

Im Zusatzversicherungsbereich könnte etwas anderes gelten. Leider stehen nach derzeitigem Kenntnisstand keine flächendeckenden und schweizweiten Informationen zur

233 Poledna/Berger, Öffentliches Gesundheitsrecht.

234 Eugster, Krankenversicherung, Rz. 758.

235 Bundesamt für Gesundheit (ed.), Kennzahlen der Schweizer Spitäler 2004, S. 12.

236 Vgl. hierzu I.3.2. und II.1.1.2.

237 Vgl. hierzu II.3.

238 Vgl. hierzu II.3.1.4. 
Verfügung, inwieweit die einzelnen Tarife tatsächlich voneinander abweichen. Jedoch dürfte die Tatsache, daß einzelne Versicherungen ihre Versicherten verpflichtet haben, die Halbprivat- oder Privatabteilungen eines bestimmten Spitals aufzusuchen, einerseits dafür sprechen, daß dadurch Auslastung erreicht und kostendeckend gewirtschaftet werden kann, andererseits die Bindung an nur einen Versicherer aber nicht unbedingt einen besseren Preis erwarten läßt.

\subsection{Konzentrationsprozeß}

Bei den Schweizer Spitälern ist über den bereits genannten Rückgang in der Anzahl $^{239}$ hinaus auch zu verzeichnen, daß es insgesamt zu einem Konzentrationsprozeß gekommen ist. Einmal gibt es einen deutlichen Rückgang von 1990 bis 2002, was die Länge des Krankenhausaufenthaltes betrifft, nämlich von durchschnittlich 13,2 Tagen auf 9,2 Tage. 240 Des weiteren hat die Anzahl der Betten in den Krankenhäuser abgenommen: Gab es 1990 noch 6,5 Betten pro 1000 Einwohnern, so waren es 2002 nur noch 3,9 Betten. ${ }^{241}$ Dem kommt gleich, daß im selben Zeitraum die Auslastung der Betten zugenommen hat, nämlich von $79 \%$ auf $85 \% .242$

Inwieweit dies mit den Steuerungselementen, insbesondere durch die Vorgaben der Spitalplanung und der Erstellung der Spitallisten, zusammenhängt, bedürfte einer eingehenden Untersuchung. Zu beachten ist dabei, daß sich die Spitäler insgesamt betriebswirtschaftlicher ausgerichtet und damit vermehrt neu aufgestellt haben, ${ }^{243}$ so daß vorgenannte Indikatoren eines Konzentrationsprozesses auch daraus resultieren können.

\subsection{Fusionen}

Fusionen von Spitälern können Wettbewerbsvorteile schaffen. Tatsächlich liegen keine Zahlen vor, inwieweit der Konzentrationsprozeß im Spitalwesen mit der Fusion von Spitälern zu tun hat. Rechtlich und insbesondere hinsichtlich des KG wird man danach zu urteilen haben, ob die Fusionen zwischen öffentlichen Spitälern oder zwischen privaten Spitälern stattfinden. Die Fusion öffentlicher Spitäler wird dem Grunde nach kaum dem Anwendungsbereich des KG unterliegen, weil Art. 3 KG Vorbehalte kantonaler Normen kennt. Da sich die Fusionen entweder auf Gesetzesgrundlage vollziehen oder sich aber in den Gesundheitsgesetzen oder Organisationsgesetzen Vorschriften

239 Vgl. hierzu II.4.1.

240 OECD Health Data 2005, Chart 2.30.

241 Ebenda, Chart 2.12.

242 Ebenda, Chart 2.13.

243 Vgl. hierzu insgesamt Oggier, Spitalfinanzierungsmodelle, sowie die Beiträge von Müller, Überlegungen zur Privatisierung; Bertschinger, Konzernrechtliche Fragen; Staffelbach, Privatisierung öffentlicher Spitäler; Schwarz, Das Zuger Modell; Barmettler, Reform Obwalden; und Eichenberger, Wettbewerb aus Sicht der Spitäler. 
über die Wirtschaftlichkeit öffentlichen Handelns finden, wird man hierin wohl einen Vorbehalt zu sehen haben. Insgesamt und für die privaten Spitäler insbesondere darf darauf verwiesen werden, daß das Kartellgesetz in seinem Art. 9 als meldepflichtige Fusionen nur solche Unternehmensfusionen bezeichnet, die zu einem Gesamtjahresumsatz von mindestens $500 \mathrm{Mio}$. CHF in der Schweiz oder von mindestens $2 \mathrm{Mrd}$. CHF weltweit führen. Aber auch hinsichtlich der Marktbeherrschung gilt es den Art. $11 \mathrm{KG}$ $\mathrm{zu}$ beachten, wonach bei überwiegend öffentlichem Interesse Fusionen nicht zu beanstanden sind.

\section{Wettbewerb zwischen Versicherungen}

\subsection{Obligatorische Krankenversicherung}

Die Krankenversicherer, die dem KVG unterstehen, dürfen keine Gewinnerzielung beabsichtigen, jedenfalls nicht für den Bereich, auf dem sie aufgrund des KVG tätig sind. Trotz alle dem sind die Krankenversicherer zum größten Teil bestrebt, auf dem für sie eher unvollkommenen Markt an Versicherten zu gewinnen, nicht zuletzt weil dies ein Mehr an Prämien verspricht und so für das eigene Überleben sorgt. Immerhin hat ein starker Konzentrationsprozeß stattgefunden, der aus ehemals weit über 1000 Krankenversicherer vor einem Vierteljahrhundert zu einer Gesamtzahl von 95 Krankenversicherern geführt hat.

\subsubsection{Struktur}

Nach Art. 11 KVG soll die obligatorische Krankenversicherung einerseits von den sozialen Krankenkassen gemäß Art. 12 KVG und andererseits von den privaten Versicherungseinrichtungen gemäß Art. $13 \mathrm{KVG}$ durchgeführt werden. Dem Wunsch des Gesetzgebers nach sollte erreicht werden, daß neben den bestehenden sozialen Krankenkassen auch private Versicherungsunternehmen im KVG eine Rolle spielen. Gesetzt wurde auf deren Know-how, insbesondere hinsichtlich von Finanzfragen. Deswegen wurden die Bedingungen, als Versicherer des KVG zu agieren, im Art. 13 KVG nicht zu restriktiv verfaßt. Der Erfolg dieses gesetzgeberischen Willens ist aber bislang nicht eingetreten. Vielmehr läßt sich sagen, daß dieses Konzept nicht aufgegangen ist: Denn tatsächlich ist seit Inkrafttreten des KVG vor etwa 13 Jahren kein einziges privates Versicherungsunternehmen auf den Markt ,gedrängt“.

Die obligatorische Krankenversicherung wird weiterhin nur von den sozialen Krankenkassen betrieben, die nun grundsätzlich neben juristischen Personen des öffentlichen Rechts auch juristische Personen des privaten Rechts sein dürfen, allerdings mit der Einschränkung des Art. $12 \mathrm{KVV}$, wonach sie nur Vereine, Stiftungen, Genossenschaften oder Aktiengesellschaften mit anderem als wirtschaftlichen Zweck nach Art. 620 Abs. III OR sein dürfen. 


\subsubsection{Marktauftreten}

Der Wettbewerb um Patienten hängt vom Verhalten der Versicherer auf dem Markt ab. Das Gesetz läßt ihm zahlreiche Spielräume, um sich von anderen Versicherern zu unterscheiden oder ihnen gleichzutun. So kann der Versicherer Wahlfranchisen, Bonusversicherungen, Hausarzt-, HMO- und Preferred-Provider-Modelle anbieten, um Patienten zu gewinnen. Darüber hinaus ist es dem Versicherer gestattet, vom System des tiers payant abzuweichen und das für die Versicherten attraktivere Systeme des tiers garant anzubieten. ${ }^{244}$ Weiterhin ist es die Entscheidung einer jeden Versicherung, ob es seinen Tätigkeitsbereich ausdehnt, schweizweit oder in bestimmten Regionen seine Versicherung anbietet, oder sich eher auf einen Kanton beschränkt und direkten Kontakt zum Kunden sucht. Des weiteren kann zur Attraktivität des Versicherers führen, wenn sie, wie es ihr Art. 12 Abs. 2 KVG gestattet, auch Zusatzversicherungen anbietet, so daß dem Kunden Pakete aus einer Hand angeboten werden. Schließlich darf sich der Versicherer um gute Risiken bemühen und dafür Werbung machen; was jedoch nichts daran ändert, daß er nicht nach Risiken selektieren darf.

\subsubsection{Prämiengestaltung}

Ein wichtiger Aspekt des Marktauftretens ist sicherlich die Höhe der Prämien. Denn für viele Versicherte ist letztlich die Prämie für die Wahl der Versicherung entscheidend. Hierbei ist die Versicherung allerdings nicht ganz frei. Erstens müssen Prämien vom Bundesamt für Gesundheit genehmigt werden. Zweitens, und eng verknüpft mit letzterem, ruft dies immer die Preisüberwachung nach Art. 14 PüG auf den Plan. Der Preisüberwacher kontrolliert hierbei, ob es sich nicht um einen Marktmißbrauch in der Preisbildung handelt. ${ }^{245}$

Bei der Gestaltung der Prämien sind folgende Gesichtspunkte zu beachten: Finanzielle Entwicklung der Krankenkasse im Prämienjahr, Betriebsergebnisse der Vorjahre und das Budget des Prämienjahres. Darüber hinaus: die Entwicklung des Versichertenstandes, die Auswirkungen des Risikoausgleiches und die aktuelle Finanzlage. ${ }^{246}$ Keinesfalls dürfen die Prämien zu einer Unterdeckung führen, weil man etwa durch Dumping-Prämien hofft, neue Versicherte zu gewinnen.

\subsubsection{Risikoausgleich}

Mittels des Risikoausgleichs zwischen den Versicherern wird versucht, schlechte Risiken in der Mitgliederstruktur auszugleichen, um der Entsolidarisierung zu begegnen. ${ }^{247}$ Nach Art. 105 KVG und der VORA 248 werden zunächst 15 Altersgruppen ge-

\section{Siehe II.2.1.5.}

245 Siehe I.4.2.

246 Eugster, Krankenversicherung, Rz. 1017.

247 Zur Beurteilung des Risikoausgleichs vgl. aus ökonomischer Sicht: Spycher, Risikoausgleich; und Beck, Risiko Krankenversicherung; sowie aus juristischer Sicht: Baumann, Der Risikoausgleich. 
bildet und diese nach Geschlecht aufgeteilt, so daß insgesamt 30 Risikogruppen entstehen. Dies geschieht für jeden Kanton, so daß insgesamt 780 Risikogruppen zu bewerten sind. Für jeden Kanton werden dann die Durchschnittskosten der einzelnen Risikogruppen sowie die Durchschnittskosten für alle Versicherten berechnet. Weichen die Durchschnittkosten einer Risikogruppe von den Durchschnittskosten aller Versicherten im Kanton ab, löst dies einen Ausgleich hinsichtlich der Risikogruppe aus: Der Differenzbetrag ist entweder zu erstatten oder berechtigt selbst, eine Ausgleichsbetrag verlangen zu dürfen. Für die Krankenkasse heißt dies, daß sie für jedes Mitglied einer Risikogruppe im Kanton entweder einen Betrag abzugeben hat oder einen Betrag erhält. Da jede Krankenkasse sowohl gute wie schlechte Risiken versichert und damit über Mitglieder verfügt, die hinsichtlich des Risikoausgleichs eine Zahlung auslösen oder zum Empfang eines Betrages berechtigen, wird in jedem Kanton nur der Saldo zwischen Abgaben und Ausgleichsbeträgen für jede einzelne Krankenkasse ermittelt und erst danach zwischen den Krankenkassen ausgeglichen. 249

Der Risikoausgleich orientiert sich nur an den Ausgaben. Für die Versicherer, die über viele gute Risiken, vor allem über viele junge Männer, verfügen, führt der Risikoausgleich nach dem Solidaritätsprinzip zu hohen Ausgleichszahlungen. Anders herum gewendet, bedeutet dies eventuell auch ein Umdenken innerhalb des Marktverhaltens: Wer schlechtere Risiken einwirbt, kann die Höhe der Ausgleichszahlungen senken.

\subsection{Zusatzversicherung}

Der Zusatzversicherungsmarkt ${ }^{250}$ ist aufgrund seiner Struktur und der Möglichkeit, Gewinne zu erzielen, attraktiv genug, daß private Anbieter ihre Produkte dort anbieten. Aber auch die sozialen Krankenkassen bieten Zusatzversicherungen an, wozu sie nach Art. $12 \mathrm{KVG}$ berechtigt sind, jedoch dabei keinen Erwerbszweck verfolgen dürfen. Das Zusammentreffen von privaten Anbietern und sozialen Krankenkassen auf einem Markt führt zu Problemen:

Zum einen sind die sozialen Krankenkassen faktisch schon erste Ansprechpartner für die Versicherten bei Vertragsabschlüssen, weil jene sich in einer obligatorischen Krankenversicherung versichern müssen. Damit haben die sozialen Krankenkassen einen gewissen Vorteil, vor allem wenn sie „Gesamtpakete“ anbieten, also die obligatorische Versicherung, eventuell mit Wahlfranchise, mit Zusatzversicherungsleistungen verbinden. Schon dadurch kann bei sehr großen Krankenkassen - eine z.B. verfügt über fast 800.000 Mitglieder - sehr schnell das Marktverhalten im KVG Einfluß auf den Markt

248 Verordnung über den Risikoausgleich in der Krankenversicherung vom 12. April 1995 (SR. 832.112.1).

249 Schneider, Risikoausgleich, S. 315-316

250 Überwacht wurde dieser Markt bis zum 31. Dezember 2008 vom Bundesamt für Privatversicherungen. Seit dem 1. Januar 2009 ist die Eidgenössische Finanzmarktaufsichtsbehörde FINMA zuständig. 
nach dem VVG haben. Darin könnte je nach Einzelfall eine unzulässige Verhaltensweise eines marktbeherrschenden Unternehmens nach Art. 7 KG gesehen werden. Bedeutsam ist dies deswegen, weil in solch einem Fall ein Vorbehalt nach Art. $3 \mathrm{KG}$ die sozialen Krankenkassen nicht vor der Anwendbarkeit des Kartellgesetzes schützt, spielt sich doch das Zusatzversicherungswesen innerhalb des VVG ab, der grundsätzlich den Wettbewerb nicht durch Vorbehalte gestaltet. Allerdings ist der Vorteil, den die Krankenkassen einst hatten, weil sie aus einer Hand Gesamtlösungen anbieten konnten, heute kaum mehr feststellbar. Die einstige Dominanz vor Verabschiedung des neuen KVG relativierte sich schon 2001, als die Krankenkassen mit 1.7 Mrd. CHF weniger Prämien für Einzelkrankenversicherungen verzeichneten als die privaten Versicherer mit 2.7 Mrd. CHF ${ }^{251}$, und erfuhr 2005 einen noch größeren Bedeutungsverlust, als die Krankenkassen mit $1 \mathrm{Mrd}$. CHF deutlich weniger Prämien für Einzelkrankenversicherungen verzeichneten als die privaten Versicherer mit 3.3 Mrd. CHF 252. Dieses Ergebnis wurde im Jahre 2007 wiederum in fast der gleichen Höhe erreicht. ${ }^{253}$

Zum anderen ist es, trotz des Rückgangs an Bedeutung, ein grundsätzlicher Anachronismus des Schweizer Systems, daß sich die sozialen Krankenkassen weiterhin auf dem Zusatzversicherungsmarkt betätigen dürfen. ${ }^{254}$ Schon verfassungsrechtlich ist zu bedenken ${ }^{255}$, ob die Wettbewerbsneutralität des Staates ${ }^{256}$ und damit auch der mittelbaren Staatsverwaltung in Form von sozialen Krankenkassen es überhaupt erlaubt, daß der Staat auf einem Bereich agiert, den Private durchaus erfüllen können und auch erfüllen. Darüber hinaus ist es, wie bereits dargelegt ${ }^{257}$, schon fraglich, worin die Notwendigkeit bestehen soll, daß die Krankenkassen dort agieren dürfen, wenn sie gerade bei der Prämiengestaltung für ältere und krankheitsanfälligeren Personen ebenso Risikoselektion betreiben wie die Privaten. Letzterem und in Hinsicht zur Wettbewerbsneutralität kann nur zu Gute gehalten werden, daß die sozialen Krankenkassen dadurch nicht in den Markt durch soziale Elemente eingreifen, was aber nochmals zu der Frage führt, warum sie dann überhaupt Zusatzversicherungen anbieten dürfen.

Jedenfalls kommen auch die privaten Versicherungsunternehmen untereinander mit ihrem Verhalten leicht in die Nähe von Verbotsnormen des KG. Nicht zuletzt die Tatsache, daß sich viele Versicherungspolicen nicht mehr voneinander unterscheiden, sei es hinsichtlich der Leistungen, sei es hinsichtlich der Prämien, könnte die Wettbewerbs-

251 Statistik des Bundesamts für Privatversicherungen über die Zusatzkrankenversicherungen 2001: http://www.finma.ch/archiv/bpv/d/dokumentation/01012/01014/01023/01101/index.html?lang=de

252 Statistik des Bundesamts für Privatversicherungen über die Zusatzkrankenversicherungen 2005: http://www.finma.ch/archiv/bpv/d/dokumentation/00909/00911/00944/00963/index.html?lang=de

253 Statistik des Bundesamts für Privatversicherungen über die Zusatzkrankenversicherungen 2007: http://www.finma.ch/archiv/bpv/d/dokumentation/00439/01389/01393/01404/01427/index.html?lan $\mathrm{g}=\mathrm{de}$

254 Siehe hierzu schon die vorangehende Kritik bei II.2.2.

255 Egli, Einheitskasse oder verzerrter Wettbewerb, S. 45-56.

256 Vgl. I.4.1.

257 Siehe II.2.2. 
kommission auf den Plan rufen, damit diese überprüft, ob sie aufgrund des Art. $5 \mathrm{KG}$, Verbot wettbewerbswidriger Absprachen, eine Ermittlung einleiten wird. ${ }^{258}$

\section{Ergebnisse: Wahl und Wettbewerb im regulierten System}

Der Wettbewerb im Spitalwesen zeichnet sich durch zwei kontradiktorische Elemente aus. Erstens gibt es überall dort, wo sich die Rechtsverhältnisse eindeutig nur dem Privatrecht zuordnen lassen, den fast vollkommenen Schutz durch die Wettbewerbsgesetze, was zunächst auch nicht sonderlich verwundert. Zweitens gibt es überall dort, wo das KVG als öffentliches Recht zum Tragen kommt, kaum einen Schutz durch das KG. Diese Einschätzungen könnten leicht dazu führen, zu behaupten, daß die Wettbewerbselemente im Bereich des KVG überhaupt keine Rolle spielen.

Dem ist aber erstens entgegenzuhalten, daß zwar oftmals nicht das KG zum Tragen kommt, allerdings andere Wettbewerbsgesetze, wie etwa das PüG, sehr wohl Anwendung finden. Darüber hinaus gibt es schon im KVG selbst Vorschriften zur Bekämpfung von Wettbewerbseinschränkungen. Dem kommt gleich, daß das KVG vor allem viele Vorschriften kennt, die eine Art von Wettbewerb überhaupt erst fördern. Dies nicht zuletzt deswegen, weil bei den Beratungen zum KVG wesentliche Beiträge von der Wettbewerbskommission selbst kamen.

In den einzelnen Marktbereichen kann man insgesamt verzeichnen, daß die Wettbewerbselemente höchst unterschiedlich ausgeprägt sind:

Das Verhältnis des Versicherten zum Spital, vor allem sein Recht ein Spital auszuwählen, ist aufs Engste mit Vorgaben der Sicherung der kantonalen Gesundheitsvorsorge verknüpft. Dadurch ist es dem Versicherten bei nicht medizinischen Gründen zwar nicht verwehrt, ein anderes Spital aufzusuchen, allerdings werden nicht alle Kosten automatisch übernommen, hat der Versicherte somit ein finanzielles Risiko für seine Wahlfreiheit zu erwägen. Diese ordre-public-Vorschriften engen die Wahlfreiheit faktisch wie rechtlich unnötigerweise ein. Der Grund für diese Vorkehrungen ist zwar von essentieller Bedeutung für die kantonale Gesundheitsversorgung, doch ist dies in zahlreichen Fällen nicht erkennbar, vor allem weil die Versicherten somit in Zusatzversicherungen gedrängt werden.

Die Wahlmöglichkeiten des Versicherten hinsichtlich der Krankenversicherung bieten ein breites Spektrum innerhalb des Obligatoriums. Die Wahlmöglichkeiten und der Kontrahierungszwang seitens der Versicherer sind eines der Kernelemente, um überhaupt sozial verträglichen Wettbewerb zu organisieren.

Das Verhältnis der Spitäler untereinander ist ebenfalls von ordre-public-Vorgaben gekennzeichnet, die wiederum auf den Erhalt der öffentlichen Spitäler abzielen. Jedoch zeigt sich hierbei, daß zahlreiche private Spitäler sich nicht nur ohne jede staatliche 
Subvention behaupten, sondern durch Spezialisierung ihre Nische gefunden haben. Die deutliche Bevorzugung der öffentlichen Spitäler hat nicht zur Verdrängung der privaten geführt, vielmehr haben die öffentlichen zahlenmäßig deutlicher abgenommen. Darüber hinaus bleibt festzuhalten, daß die Teilrevision des KVG, grundsätzlich in Kraft getreten zum 1. Januar 2009, die Position der privaten Spitäler gestärkt hat, indem einige Bevorzugungen öffentlicher Spitäler abgebaut worden sind.

Das Verhältnis der Spitäler zu den Versicherern ist rechtlich geprägt von einem relativ großen Gestaltungsspielraum hinsichtlich der Tarifverträge. Schon die Vorgaben des KVG vor den Reformen zum 1. Januar 2009 führten faktisch nicht dazu, daß neue Impulse, wie etwa SwissDRG, nicht in das System aufgenommen werden konnten. Dort erweist sich sogar insgesamt das eher wettbewerbshindernde Element der horizontalen Kollektivverträge als fruchtbar für die Grundbedingungen von Wettbewerb.

Das Verhältnis der obligatorischen Krankenversicherer untereinander wird von vornherein dadurch getrübt, daß sich bis heute kein einziges privates Unternehmen jemals als Krankenversicherer nach dem KVG betätigt hat. Deswegen können die sogenannten Wettbewerbselemente bisher nicht ausreichend sein, weil nur die alten sozialen Krankenkassen - trotz der gesetzgeberischen Intention - den Markt unter sich aufteilen. Hinzu kommt noch, daß die sozialen Krankenkassen unnötigerweise und verfassungsrechtlich problematisch den privaten Anbietern auf dem Zusatzversicherungsmarkt Konkurrenz machen. Letztlich ist aber das teilweise nahezu einheitliche Auftreten der privaten Zusatzversicherer, was Leistungsangebot und Prämiengestaltung betrifft, schon Grund genug zur Besorgnis hinsichtlich eines nicht gerade wettbewerbsfördernden Verhaltens.

Insgesamt zeigen die einzelnen Verhältnisse und Märkte deutlich die Unterschiede hinsichtlich der Wettbewerbselemente auf. Damit kann jedenfalls festgehalten werden, daß Wettbewerb in der obligatorischen Krankenversicherung schon heute eine Rolle spielt und vor allem auch wichtige Funktionen wahrnimmt. Dies wäre graduell auszubauen. Dabei muß man sich vergewissern, daß gerade solche Vorschriften, die auf den ersten Blick eher Wettbewerb zu hindern scheinen, teilweise als Grundpfeiler erst dafür sorgen, daß Wettbewerb überhaupt sozial verträglich stattfinden kann. 


\section{Literatur}

Bartmettler, Jost, Reform des Kantonsspitals Obwalden in zwei Schritten, in: Hürlimann, Barbara/ Poledna, Thomas/ Rübel, Martin (ed.), Privatisierung und Wettbewerb im Gesundheitswesen, Zürich 2000, S. 87-100.

Baumann, Meret, Der Risikoausgleich im KVG - ein Ausgleich des Risikos?, in: Schweizerische Zeitschrift für Sozialversicherung und berufliche Vorsorge (SZS) 2005, S. 370-409.

Baumberger, Jürg, Managed Care, in: Kocher, Gerhard/Oggier, Willy (ed.), Gesundheitswesen Schweiz 2007-2009: Eine aktuelle Übersicht, 3. Auflage, Bern 2007, S. 171-179.

Beck, Konstantin, Risiko Krankenversicherung: Risikomanagement in einem regulierten Krankenversicherungsmarkt, Bern u.a. 2004.

Bertschinger, Urs, Konzernrechtliche Fragen bei der Privatisierung öffentlicher Spitäler, in: Hürlimann, Barbara/ Poledna, Thomas/ Rübel, Martin (ed.), Privatisierung und Wettbewerb im Gesundheitswesen, Zürich 2000, S. 37-63.

Boos, Leo, Soziales Dilemma und die Organisation des Krankenhauses: Die Aufgaben des Spitalmanagements, Bern 2002.

Borer, Jürg, Kartellgesetz. Kommentar, Zürich 2005.

Bundesamt für Gesundheit (ed.), Kennzahlen der Schweizer Spitäler 2005, Bern 2008.

Bundesamt für Gesundheit (ed.), Kennzahlen der Schweizer Spitäler 2004, Bern 2006

Bundesamt für Gesundheit (ed.), Statistik der obligatorischen Krankenversicherung 2003, Bern 2004.

Bundesamt für Gesundheit (ed.), Statistik der obligatorischen Krankenversicherung 2007 - Teil: Graphiken und Kommentare, Bern 2009.

Bundesamt für Gesundheit (ed.), Statistik der obligatorischen Krankenversicherung 2007 - Teil: Tabellen und Beilagen, Bern 2009.

Bundesamt für Sozialversicherungen (ed.), Schweizerische Sozialversicherungsstatistik 2008, Bern 2008.

Bundesamt für Sozialversicherungen (ed.), Schweizerische Sozialversicherungsstatistik 2004, Bern 2004.

Bundesamt für Statistik (ed.), Beschäftigte im Gesundheitswesen. Fakten und Trends auf der Basis der Betriebszählungen von 1995 bis 2005 (BfS Aktuell, 14 Gesundheit, November 2007), Neuchâtel 2007.

Bundesamt für Statistik (ed.), Krankenhausstatistik 2007 - Standardtabellen: Definitive Resultate (BfS Aktuell, 14 Gesundheit, März 2009), Neuchâtel 2009.

Bundesamt für Statistik (ed.), Medizinische Statistik der Krankenhäuser 2007 - Standardtabellen: Definitive Resultate (BfS Aktuell, 14 Gesundheit, März 2009), Neuchâtel 2007.

Bundesamt für Statistik (ed.), Spitalaufenthalte im Überblick: Ergebnisse aus der medizinischen Statistik der Krankenhäuser 2005, Neuchâtel 2007.

Egli, Philipp, Einheitskasse oder verzerrter Wettbewerb: Eine wirtschaftsverfassungsrechtliche Würdigung der Organisation der Krankenversicherer unter besonderer Berücksichtigung der aktuellen Diskussion um die Einheitskasse, Zürich/Basel/Genf 2006.

Ehrenzeller, Bernhard/Mastronardi, Philippe/Schweizer, Rainer J./Vallender, Klaus A., Die schweizerische Bundesverfassung - Kommentar, 2. Auflage, Zürich/Basel/Genf 2008.

Eichenberger, Thomas, Wettbewerb aus der Sicht der Spitäler, in: Hürlimann, Barbara/ Poledna, Thomas/ Rübel, Martin (ed.), Privatisierung und Wettbewerb im Gesundheitswesen, Zürich 2000, S. 133156.

Eugster, Gebhard, Die Unterscheidung zwischen grund- und zusatzversicherten Leistungen im Spitalbereich: Welche juristischen Kriterien sind massgeblich, in: Gächter, Thomas (ed.), Spitalfinanzie- 
rung: Spitäler im Spannungsverhältnis zwischen Grund- und Zusatzversicherung, Bern/Luzern 2005, S. 15-46.

Eugster, Gebhard, Krankenversicherung, in: Meyer, Ulrich (ed.), Soziale Sicherheit, 2. Auflage (= Schweizerisches Bundesverwaltungsrecht, Band XIV), Basel/Genf/München 2007, S. 337-823.

Finsterwald, Daniel, Managed Care - Pionierland Schweiz, Bern 2004.

Gächter, Thomas (ed.), Außerkantonale Hospitalisation: Eine Tür zu mehr Wettbewerb im Gesundheitswesen?, Bern 2006.

Gächter, Thomas (ed.), Spitalfinanzierung: Spitäler im Spannungsverhältnis zwischen Grund- und Zusatzversicherung, Bern/Luzern 2005.

Gächter, Thomas/Vollenwieder, Irene, Gesundheitsrecht, Basel 2008.

Hanhart, Roger, Diagnosebezogene Fallpauschalen - Ein Risiko für die Krankenversicherer? Welche Gefahren beinhalten AP-DRG? Bern 2004.

Heusser, Markus, Öffentliche und private Spitäler: Finanzierung, Rechnungslegung und Marktverhalten, Bern/Stuttgart/Wien 1996.

Indra, Peter, Die Einführung von SwissDRGs in Schweizer Spitälern und ihre Auswirkungen auf das schweizerische Gesundheitswesen, Zürich/Bern 2004.

Jordi, Michael, Bedeutung der außerkantonalen Hospitalisation für die Kantone, in: Gächter, Thomas (ed.), Ausserkantonale Hospitalisation: Eine Tür zu mehr Wettbewerb im Gesundheitswesen? Bern. 2006, S. 87-102.

Lauterburg, Margareta, Gesundheits- und Versicherungsmärkte: Kartellrechtliche Fragen in der Praxis der Wettbewerbsbehörde, in: Hürlimann, Barbara/ Poledna, Thomas/ Rübel, Martin (ed.), Privatisierung und Wettbewerb im Gesundheitswesen, Zürich 2000, S. 101-132.

Locher, Heinz, Die Vertreibung aus dem Schlaraffenland: Irrtümer der schweizerischen Gesundheitspolitik und Vorschläge zu ihrer Korrektur, in: Schaffhauser, René/ Locher, Heinz/ Poledna, Thomas (ed.), Das Gesundheitswesen - Motor von Wohlbefinden und Wohlstand: Radikale Denkanstösse für das schweizerische Gesundheitswesen, St. Gallen 2006, S. 79-122.

Malk, Rolf/Kampmann, Thorsten/Indra, Peter (ed.), DRG-Handbuch Schweiz, Grundlagen, Auswirkungen, Anwendungen und praktische Tipps für Anwender, Bern 2006.

Maurer, Alfred, Bundessozialversicherungsrecht, 2. Auflage, Bern u.a. 1993.

Maurer, Alfred, Das neue Krankenversicherungsrecht, Basel u.a. 1996.

Meyer, Beat, Schranken und Freiräume von Art. 41 KVG, in: Gächter, Thomas (ed.), Ausserkantonale Hospitalisation: Eine Tür zu mehr Wettbewerb im Gesundheitswesen? Bern. 2006, S. 1-16.

Müller, Andreas, Grundlegende Überlegungen zur Privatisierung öffentlicher Spitäler, in: Hürlimann, Barbara/ Poledna, Thomas/ Rübel, Martin (ed.), Privatisierung und Wettbewerb im Gesundheitswesen, Zürich 2000, S. 9-36.

Oggier, Willy, Spitalfinanzierungsmodelle für die Schweiz: Trends und Empfehlungen aus Sicht der Gesundheitsökonomie, Bern u.a. 1999.

Poledna, Thomas, Gesundheitsrecht und Wettbewerb: Der schmale Pfad zwischen Plan und Markt, in: Schaffhauser, René/ Poledna, Thomas (ed.), Wettbewerb im Gesundheitsrecht. Krankenversicherung, Arzt und Arzneimittel zwischen staatlicher Lenkung und Markt, St. Gallen 2004, S. 27-54.

Poledna, Thomas/Berger, Brigitte, Öffentliches Gesundheitsrecht, Bern 2002.

Rich, Lukas, Die geplante Umsetzung der neuen Spitalfinanzierung im Kanton Zürich: Eine kritische Betrachtung, Jusletter vom 19.1.2009 (www.jusletter.ch).

Schaller, Oliver/Tagman, Christoph, Kartellrecht und öffentliches Recht: Neuere Praxis im Bereich des Gesundheitswesens, Aktuelle juristische Praxis (AJP) 2004, 704-711. 
Schneider, Beat, Solidarität zwischen den Geschlechtern und den Generationen: Der Risikoausgleich in der sozialen Krankenversicherung, Soziale Sicherheit (CHSS) 1995, 314-317.

Schüpfer, Guido/ Konrad, Christoph/Staffelbach, Bruno, Privatisierung von öffentlichen Spitälern in der Schweiz: Gedanken aus ärztlicher Sicher, in: Hürlimann, Barbara/ Poledna, Thomas/ Rübel, Martin (ed.), Privatisierung und Wettbewerb im Gesundheitswesen, Zürich 2000, S. 65-73.

Schwarz, Andreas, Privatisierung öffentlicher Spitäler: Das Zuger Modell, in: Hürlimann, Barbara/ Poledna, Thomas/ Rübel, Martin (ed.), Privatisierung und Wettbewerb im Gesundheitswesen, Zürich 2000, S. 75-85.

Seitz, Claudia, Autonomie der Regionen bei Steuerregelungen: Neuere Entwicklungen im europäischen Beihilferecht und ihre Bedeutung für die Schweiz, Aktuelle juristische Praxis (AJP) 2007, S. 415423.

Spycher, Stefan, Risikoausgleich in der Krankenversicherung: Notwendigkeit, Ausgestaltung und Wirkungen, Bern u.a. 2002.

Streit, Peter, Zusatzversicherungen nach Versicherungsvertragsgesetz (VVG): Erfahrungen und Entwicklungen, Soziale Sicherheit (CHSS) 1997, S. 222-224.

Undritz, Nils, Krankenhaus, in: Kocher, Gerhard/Oggier, Willy (ed.), Gesundheitswesen Schweiz 20012002: Eine aktuelle Überblick, Solothurn 2001, S. 97-107.

Winkler, Andreas, Integrierte Versorgung - Spitäler und Ärztenetze im Verbund: Interessengemeinschaft Leistungserbringer integriertes Managed Care Thurgau (ILIT) - ein praxisorientiertes Projekt, Bern 2004.

Zäch, Roger/Heizmann, Reto A., Markt und Marktmacht, in: Geiser, Thomas/ Krauskopf Patrick/ Münch, Peter, Schweizerisches und europäisches Wettbewerbsrecht, Basel/Genf/München 2005, S. 29-62.

Zahnd, Daniel, Kennzahlen der Schweizer Spitäler - Eine neue Statistikpublikation zur Krankenversicherung, CHSS 2008, S. 175-177. 


\title{
Regulierter Wettbewerb im schweizerischen Gesundheitswesen - Kommentar zum Bericht über die Schweiz aus ökonomischer Sicht
}

\author{
Jürg H. Sommer
}

1. Auf Expansion ausgerichtete finanzielle Anreize 416

1.1 Anreize für die Versicherten/Patienten 416

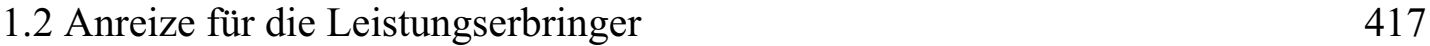

1.3 Anreize für die ergänzenden Sachwalter 418

2. Bessere marktwirtschaftliche Kontrollen 419

3. Ideale Wettbewerbsvoraussetzungen in der Schweiz 421

4. Ungenügende Reform des Krankenversicherungsgesetzes 422

5. Abbau bestehender Wettbewerbshindernisse 424

5.1 Freie Preis- und Vertragsbildung garantieren 424

$\begin{array}{ll}5.2 \text { Spitallisten abschaffen } & 424\end{array}$

5.3 Monistische Spitalfinanzierung einführen $\quad 425$

5.4 Kostenverantwortung an Ärzte übertragen 425

5.5 Sozialausgleich auf wirtschaftlich Schwache konzentrieren 427

$\begin{array}{ll}\text { Literatur } & 428\end{array}$ 